Criticality Benchmark Results

Using Various MCNP Data Libraries

Stephanie C. Frankle 



\section{DISCLAIMER}

This report was prepared as an account of work sponsored by an agency of the United States Government. Neither the United States Government nor any agency thereof, nor any of their employees, make any warranty, express or implied, or assumes any legal liability or responsibility for the accuracy, completeness, or usefulness of any information, apparatus, product, or process disclosed, or represents that its use would not infringe privately owned rights. Reference herein to any specific commercial product, process, or service by trade name, trademark, manufacturer, or otherwise does not necessarily constitute or imply its endorsement, recommendation, or favoring by the United States Government or any agency thereof. The views and opinions of authors expressed herein do not necessarily state or reflect those of the United States Government or any agency thereof. 


\section{DISCLAIMER}

Portions of this document may be illegible in electronic image products. Images are produced from the best available original document. 


\section{Table of Contents}

ABSTRACT 1

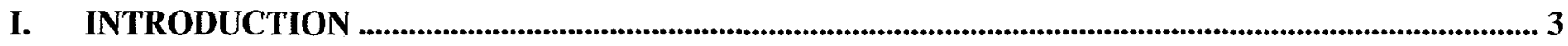

TABLE 1: CRITICALITY BENCHMARK DESCRIPTIONS FOR BARE METAL ASSEMBliES ........................................ 5

TABLE 2: CRITICALITY BENCHMARK DESCRIPTIONS FOR SOLUTION ASSEMBLIES ......................................... 5

TABLE 3: CRITICALITY BENCHMARK DESCRIPTIONS FOR WATER-REFLECTED METAL ASSEMBLIES ................... 6

TABLE 4: CRITICALITY BENCHMARK DESCRIPTIONS FOR POLYETHYLENE-REFLECTED ASSEMBLIES .................. 6

TABLE 5: CRITICALITY BENCHMARK DESCRIPTIONS FOR BERYLLIUM AND BERYLLIUM OXIDE-REFLECTED

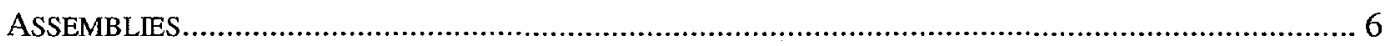

TABLE 6: CRITICALITY BENCHMARK DESCRIPTIONS FOR GRAPHITE-REFLECTED ASSEMBLIES ........................ 7

TABLE 7: CRITICALITY BENCHMARK DESCRIPTIONS FOR ALUMINUM-REFLECTED ASSEMBLIES ........................ 7

TABle 8: CRITICALITY BENCHMARK DESCRIPTIONS FOR STEEL- AND NICKEL-REFLECTED ASSEMBliES ......... 7

TABLE 9: CRITICALITY BENCHMARK DESCRIPTIONS FOR TUNGSTEN-REFLECTED ASSEMBLIES ....................... 8

TABLE 10: CRITICALITY BENCHMARK DESCRIPTIONS FOR THORIUM-REFLECTED ASSEMBLIES ........................ 8

TABLE 11: CRITICALITY BENCHMARK DESCRIPTIONS FOR NORMAL URANIUM-REFLECTED ASSEMBlies......... 8

TABLE 12: CRITICALITY BENCHMARK DESCRIPTIONS FOR HIGHLY ENRICHED URANIUM-REFLECTED ASSEMBLIES.

TABLE 13: CRITICALITY BENCHMARK DESCRIPTIONS FOR OTHER ASSEMBLIES ……......................................... 9

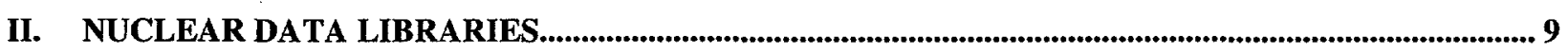

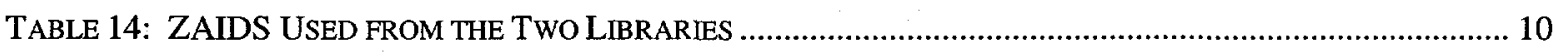

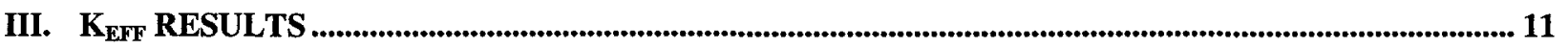

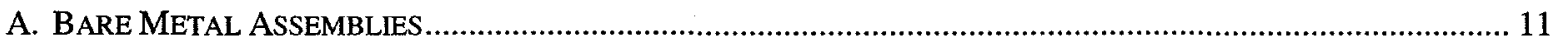

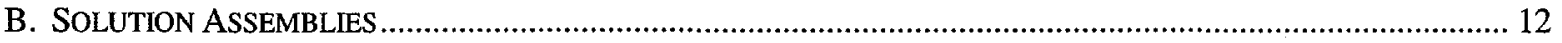

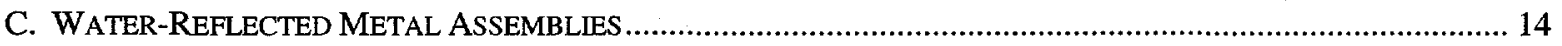

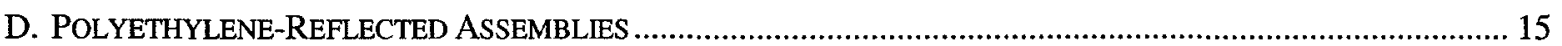

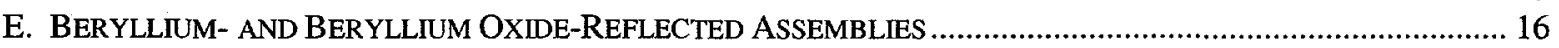

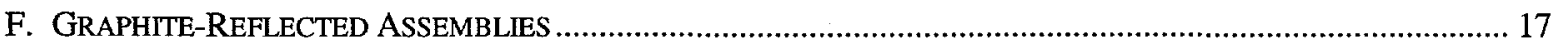

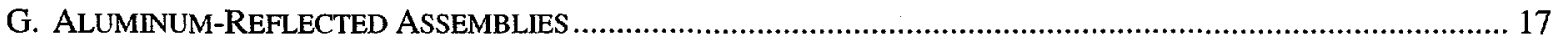

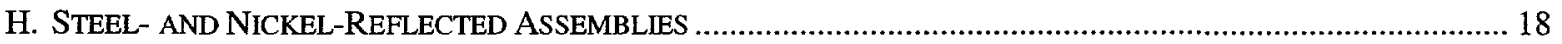

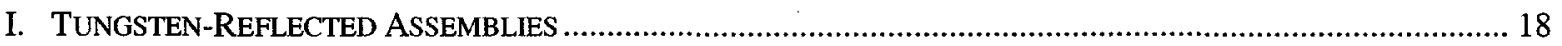

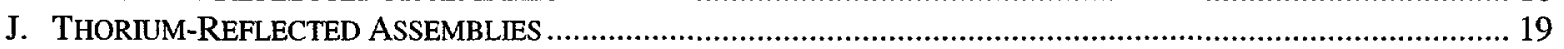

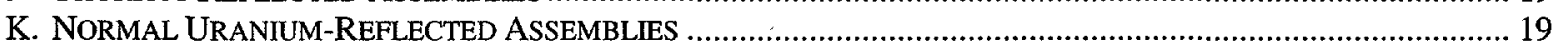

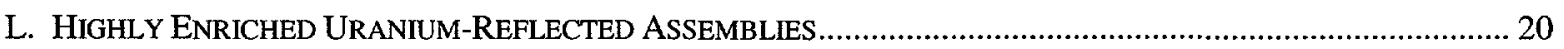

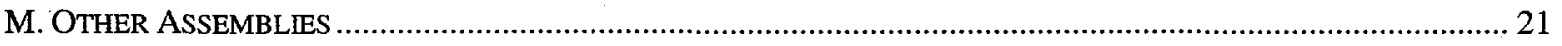

IV. SUMMARY ............................................................................................................................................................. 26

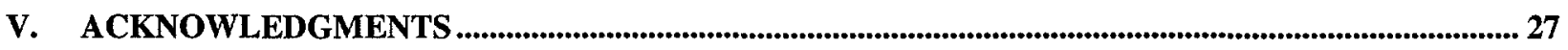

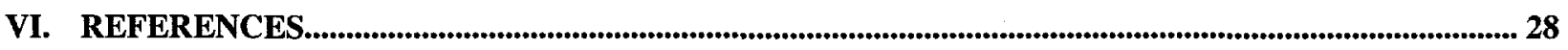




\title{
Criticality Benchmark Results Using Various MCNP Data Libraries
}

By

\author{
Stephanie C. Frankle
}

\begin{abstract}
A suite of 86 criticality benchmarks has been recently implemented in MCNP ${ }^{T M}$ as part of the nuclear data validation effort. These benchmarks have been run using two sets of MCNP continuous-energy neutron data: ENDF/B-VI based data through Release 2 (ENDF60) and the ENDF/B-V based data. New evaluations were completed for ENDF/B-VI for a number of the important nuclides such as the isotopes of $\mathrm{H}, \mathrm{Be}, \mathrm{C}, \mathrm{N}$, $\mathrm{O}, \mathrm{Fe}, \mathrm{Ni},{ }^{235,238} \mathrm{U},{ }^{237} \mathrm{~Np}$, and ${ }^{239,240} \mathrm{Pu}$.
\end{abstract}

When examining the results of these calculations for the five major categories of ${ }^{233} \mathrm{U}$, intermediate-enriched ${ }^{235} \mathrm{U}$ (IEU), highly enriched ${ }^{235} \mathrm{U}(\mathrm{HEU}),{ }^{239} \mathrm{Pu}$, and mixed metal assembles, we find the following:

- The new evaluations for ${ }^{9} \mathrm{Be},{ }^{12} \mathrm{C}$, and ${ }^{14} \mathrm{~N}$ show no net effect on $\mathrm{k}_{\text {eff. }}$

- There is a consistent decrease in $k_{\text {eff }}$ for all of the solution assemblies for ENDF/B-VI due to ${ }^{1} \mathrm{H}$ and ${ }^{16} \mathrm{O}$, moving $k_{\text {eff }}$ further from the benchmark value for uranium solutions and closer to the benchmark value for plutonium solutions.

- $k_{\text {eff }}$ decreased for the ENDF/B-VI Fe isotopic data, moving the calculated $k_{\text {eff }}$ further from the benchmark value.

- $k_{\text {eff }}$ decreased for the ENDF/B-VI Ni isotopic data, moving the calculated $k_{\text {eff }}$ closer to the benchmark value.

- The $\mathrm{W}$ data remained unchanged and tended to calculate slightly higher than the benchmark values.

- For metal uranium systems, the ENDF/B-VI data for ${ }^{235} U$ tends to decrease $k_{\text {eff }}$ while the ${ }^{238} \mathrm{U}$ data tends to increase $k_{\text {eff. }}$. The net result depends on the energy spectrum and material specifications for the particular assembly.

- For more intermediate-energy systems, the changes in the ${ }^{235,238} \mathrm{U}$ evaluations tend to increase $k_{\text {eff. }}$ For the mixed graphite and normal uranium-reflected assembly, a large increase in $k_{\text {eff }}$ due to changes in the ${ }^{238} \mathrm{U}$ evaluation moved the calculated $k_{\text {eff }}$ much closer to the benchmark value.

- There is little change in $k_{\text {eff }}$ for the uranium solutions due to the new ${ }^{235,238} \mathrm{U}$ evaluations.

- There is little change in $k_{\text {eff }}$ for the ${ }^{239} \mathrm{Pu}$ metal assemblies, but a decrease in $k_{\text {eff }}$ for the solution assemblies, moving them closer to the benchmark value.

MCNP is a trademark of the Regents of the University of California, Los Alamos National Laboratory. 


\section{Introduction}

As part of the validation process for nuclear data provided to transport codes such as MCNP, ${ }^{1}$ we have developed a comprehensive suite of 86 criticality benchmarks. ${ }^{2}$ In choosing these benchmarks, we tried to assemble a set of problems that would (1) test different energy regions, such as the high-energy region of the fast critical assemblies and the thermal region of the solution experiments; (2) test a variety of important reflector materials; and (3) not have an unreasonably high number of benchmarks. This benchmark suite by no means covers all isotopes and energy regions of interest. For example, we are awaiting new experimental measurements for intermediate-energy region (0.0001-0.100 MeV) critical assemblies ${ }^{3}$ and adequate benchmark specifications for low-enrichment uranium metal assemblies. Suitable experiments utilizing ${ }^{232}$ Th are also lacking.

Two compendiums of criticality experimental information were used in developing this suite of benchmarks: the Cross Section Evaluation Working Group (CSEWG) specifications ${ }^{4}$ and the International Criticality Safety Benchmark Evaluation Project (ICSBEP). ${ }^{5}$ The suite is composed of five major categories: critical assemblies utilizing ${ }^{233} \mathrm{U}$, intermediate-enriched ${ }^{235} \mathrm{U}$ (IEU), highly enriched ${ }^{235} \mathrm{U}$ (HEU), ${ }^{239} \mathrm{Pu}$, and mixed metal assemblies. Within each category, there are bare, reflected, and solution assemblies. A variety of reflector materials have been utilized, such as $\mathrm{Be}, \mathrm{BeO}, \mathrm{C}, \mathrm{Al}$, $\mathrm{Fe}, \mathrm{Ni}, \mathrm{W}, \mathrm{Th},{ }^{233} \mathrm{U}$, and normal (natural) uranium $\mathrm{U}(\mathrm{N})$. Tables $1-13$ contain a brief description of each of the criticality benchmarks, including its associated MCNP filename. The notation of HEU (93.5) indicates that highly enriched uranium having 93.5 weight percent of ${ }^{235} \mathrm{U}$ was used in the experiment.

We present the list of benchmarks in a different format than that used previously in LA-13594. The benchmarks have now been placed into 13 groups: bare metal assemblies, solution experiments, water-reflected metal assemblies, assemblies reflected by polyethylene, beryllium and beryllium oxide, graphite, aluminum, steel and nickel, tungsten, thorium, normal uranium, and HEU, and other experiments.

As you will note, there are two sets of specifications for five of the assemblies. For Flattop-23, a sphere of ${ }^{233} \mathrm{U}$ reflected by normal uranium, the CSEWG specification contains a small gap between the main fuel and the reflector, whereas the ICSBEP 
specification has no gap. ICSBEP specifications for Godiva contain both the standard sphere of HEU as well as nested spherical shells of HEU. There are two specifications for the one- and two-dimensional models for Bigten, and for the water-reflected sphere of HEU. The thorium-reflected sphere of ${ }^{239} \mathrm{Pu}$, Thor, also has a one- and twodimensional representation. Therefore, there are a total of $91 \mathrm{MCNP}$ input files.

For this report, we will focus only on the results from the $k_{\text {eff }}$ calculations. We calculated these benchmarks using two sets of MCNP continuous-energy data libraries: ENDF/B-VI based data through Release $2\left(\right.$ ENDF60) ${ }^{6}$ and the ENDF/B-V based data. Table 14 lists the ZAIDs used. A future report will detail the specifications for other measured quantities such as neutron leakage spectra, activation ratio measurements with a variety of materials, and central-fission ratio measurements for nine of the critical assemblies. ${ }^{7}$ Additionally, we will include fission-ratio measurements performed at NIST (National Institute of Standards and Technology). A brief description of the nuclear data libraries used in the calculations is given in the next section, followed by a discussion of the $k_{\text {eff }}$ results. The results of sensitivity tests performed to determine which nuclide was driving the changes in $\mathrm{k}_{\text {eff }}$ between data libraries are also presented. 


\section{Table 1: Criticality Benchmark Descriptions for Bare Metal Assemblies}

\begin{tabular}{|c|c|l|}
\hline $\begin{array}{c}\text { MCNP } \\
\text { Filename }\end{array}$ & 1D/2D/3D & \multicolumn{1}{c|}{ Benchmark Description } \\
\hline 23umt1 & 1D & Jezebel-23, Bare Sphere of U-233 \\
\hline ieumt3 & 1D & Bare IEU Sphere (36 wt.\%), VNIIEF \\
\hline umet1ss & 1D & Godiva, Unreflected Sphere of HEU, Simple Sphere representation \\
\hline umet1ns & 1D & Godiva, Unreflected Sphere of HEU, Nested Spherical Shell representation \\
\hline umet8 & 3D & Bare HEU Sphere, VNIITF, 3D model \\
\hline umet15 & 2D & Bare HEU Cylinder, VNIITF \\
\hline umet18 & 1D & Simplified Bare HEU Sphere, VNIIEF \\
\hline pumet1 & 1D & Jezebel-Pu (4.5\%), Bare Sphere of Pu-239 with 4.5\% Pu-240 \\
\hline pumet2 & 1D & Jezebel-Pu (20\%), Bare Sphere of Pu-239 with 20\% Pu-240 \\
\hline pumet22 & 1D & Simplified Plutonium (98\%) Bare Sphere, VNIIEF \\
\hline
\end{tabular}

Table 2: Criticality Benchmark Descriptions for Solution Assemblies

\begin{tabular}{|c|c|c|}
\hline $\begin{array}{l}\text { MCNP } \\
\text { Filename }\end{array}$ & 1D/2D/3D & Benchmark Description \\
\hline 23usl1a & $1 \mathrm{D}$ & ORNL-5, $1.0226 \mathrm{~g} / \mathrm{l}$ Unreflected 27.24 " Sphere of U-233 nitrate solution \\
\hline 23 usl1b & 1D & $\begin{array}{l}\text { ORNL-6, } 1.0253 \mathrm{~g} / \mathrm{l} \text { Unreflected } 27.24 \text { " Sphere of U-233 nitrate solution } \\
\text { with Boron }\end{array}$ \\
\hline 23usl1c & 1D & $\begin{array}{l}\text { ORNL-7, } 1.0274 \mathrm{~g} / \mathrm{l} \text { Unreflected } 27.24 \text { " Sphere of U-233 nitrate solution } \\
\text { with Boron }\end{array}$ \\
\hline 23usl1d & 1D & $\begin{array}{l}\text { ORNL-8, } 1.0275 \mathrm{~g} / \mathrm{l} \text { Unreflected } 27.24 \text { " Sphere of U-233 nitrate solution } \\
\text { with Boron }\end{array}$ \\
\hline 23usl1e & 1D & $\begin{array}{l}\text { ORNL-9, } 1.0286 \mathrm{~g} / \mathrm{l} \text { Unreflected } 27.24 \text { " Sphere of U-233 nitrate solution } \\
\text { with Boron }\end{array}$ \\
\hline $23 u s 18$ & $1 \mathrm{D}$ & $\begin{array}{l}\text { ORNL-11, } 1.0153 \mathrm{~g} / \mathrm{l} \text { Unreflected } 48.04 \text { " Sphere of U-233 nitrate solution } \\
\text { with Boron }\end{array}$ \\
\hline usol13a & 1D & ORNL-1, Unreflected Sphere of Uranyl $(20.12 \mathrm{~g} / \mathrm{l})$ Nitrate \\
\hline usol13b & $1 \mathrm{D}$ & ORNL-2, Unreflected Sphere of Uranyl (23.53 g/l) Nitrate with Boron \\
\hline usol13c & $1 \mathrm{D}$ & ORNL-3, Unreflected Sphere of Uranyl $(26.77 \mathrm{~g} / 1)$ Nitrate with Boron \\
\hline usol13d & $1 \mathrm{D}$ & ORNL-4, Unreflected Sphere of Uranyl $(28.45 \mathrm{~g} / \mathrm{l})$ Nitrate with Boron \\
\hline usol32 & $1 \mathrm{D}$ & ORNL-10. Unreflected Sphere of Uranvl $(28.45 \mathrm{a} / \mathrm{l})$ Nitrate with Boron \\
\hline pnl1 & 1D & PNL-1, Idealized (No Container) Unreflected Sphere of Pu Nitrate Solution \\
\hline pnl6 & 1D & $\begin{array}{l}\text { PNL-6, Idealized (No Container) Unreflected Sphere of Pu Nitrate Solution; } \\
\text { Revised PNL-2 }\end{array}$ \\
\hline pusl11a & 1D & PNL-3, Unreflected 18" Sphere of Pu (22.35 g/l) Nitrate Solution \\
\hline pusl11b & $1 \mathrm{D}$ & PNL-4, Unreflected 18" Sphere of Pu (27.49 g/l) Nitrate Solution \\
\hline pusl11c & $1 \mathrm{D}$ & PNL-5, Unreflected 16" Sphere of Pu $(43.43 \mathrm{~g} / \mathrm{l})$ Nitrate Solution \\
\hline pusl11d & 1D & Unreflected 16" Sphere of Pu (34.96 g/l) Nitrate Solution \\
\hline
\end{tabular}


Table 3: Criticality Benchmark Descriptions for Water-Reflected Metal Assemblies

\begin{tabular}{|c|c|l|}
\hline $\begin{array}{c}\text { MCNP } \\
\text { Filename }\end{array}$ & 1D/2D/3D & \multicolumn{1}{|c|}{ Benchmark Description } \\
\hline umet4a & 2D & Water-Reflected HEU (97.675) Sphere, with Plexiglas ring \\
\hline umet4b & 2D & $\begin{array}{l}\text { Water-Reflected HEU (97.675) Sphere, Trans. Am. Nuc. Soc. 27, pg. } 412 \\
(1977)\end{array}$ \\
\hline pumet11 & 1D & Water-Reflected alpha-phase Pu sphere \\
\hline
\end{tabular}

Table 4: Criticality Benchmark Descriptions for Polyethylene-Reflected Assemblies

\begin{tabular}{|c|c|l|}
\hline $\begin{array}{c}\text { MCNP } \\
\text { Filename }\end{array}$ & 1D/2D/3D & \multicolumn{1}{c|}{ Benchmark Description } \\
\hline umet11 & 3D & Polyethylene (CH2)-Reflected HEU( 89.6) Sphere, VNIITF \\
\hline umet20 & 1D & Polyethylene-Reflected HEU Sphere, VNIIEF \\
\hline pumet24 & 1D & Simplified Plutonium Sphere, Polyethylene Reflector, VNIIEF \\
\hline
\end{tabular}

Table 5: Criticality Benchmark Descriptions for Beryllium and Beryllium Oxide-Reflected Assemblies

\begin{tabular}{|c|c|l|}
\hline $\begin{array}{c}\text { MCNP } \\
\text { Filename }\end{array}$ & 1D/2D/3D & \multicolumn{1}{c|}{ Benchmark Description } \\
\hline 23umt5a & 1D & $0.805^{\prime \prime}$ Be-Reflected Sphere of U-233, Planet Assembly \\
\hline 23umt5b & 1D & 1.652" Be-Reflected Sphere of U-233, Planet Assembly \\
\hline umet9a & 3D & Be-Reflected HEU ( 89.6) Sphere, VNIITF \\
\hline umet9b & 3D & BeO-Reflected HEU ( 89.6) Sphere, VNIITF \\
\hline pumet18 & 1D & Be-Reflected Pu (94.79) Sphere, Planet Assembly \\
\hline pumet19 & 3D & Be-Reflected Pu ( 90) Sphere, VNIITF \\
\hline pumt21a & 2D & Be-Reflected Pu Cylinder \\
\hline pumt21b & 2D & BeO-Reflected Pu Cylinder \\
\hline
\end{tabular}


Table 6: Criticality Benchmark Descriptions for Graphite-Reflected Assemblies

\begin{tabular}{|c|c|l|}
\hline $\begin{array}{c}\text { MCNP } \\
\text { Filename }\end{array}$ & 1D/2D/3D & \multicolumn{1}{|c|}{ Benchmark Description } \\
\hline ieumt4 & 1D & Graphite-Reflected IEU Sphere (36 wt.\%), VNIIEF \\
\hline umet19 & 1D & Graphite-Reflected HEU Sphere, VNIIEF \\
\hline pumet23 & 1D & Simplified Plutonium Sphere, Graphite reflector, VNIIEF \\
\hline
\end{tabular}

Table 7: Criticality Benchmark Descriptions for Aluminum-Reflected Assemblies

\begin{tabular}{|c|c|l|}
\hline $\begin{array}{c}\text { MCNP } \\
\text { Filename }\end{array}$ & 1D/2D/3D & \multicolumn{1}{c|}{ Benchmark Description } \\
\hline ieumt6 & 1D & Duralumin-Reflected IEU Sphere (36 wt.\%), VNIIEF \\
\hline umet12 & 3D & Aluminum-Reflected HEU ( 89.6) Sphere, VNIITF \\
\hline umet22 & 1D & Duralumin-Reflected HEU Sphere, VNIIEF \\
\hline pumet9 & 1D & Aluminum-Reflected Pu (94.8) Sphere, Comet Assembly \\
\hline
\end{tabular}

Table 8: Criticality Benchmark Descriptions for Steel- and Nickel-Reflected Assemblies

\begin{tabular}{|c|c|c|}
\hline $\begin{array}{c}\text { MCNP } \\
\text { Filename }\end{array}$ & 1D/2D/3D & Benchmark Description \\
\hline & & Fe-Reflected \\
\hline ieumt5 & 1D & Steel-Reflected IEU Sphere (36 wt.\%), VNIIEF \\
\hline umet13 & 3D & St.20 Steel-Reflected HEU ( 89.6) Sphere, VNIITF \\
\hline umet21 & 1D & Steel-Reflected HEU Sphere, VNIIEF \\
\hline pumet25 & 1D & Simplified Plutonium Sphere, 1.55-cm Steel Reflector, VNIIEF \\
\hline pumet26 & 1D & Simplified Plutonium Sphere, 11.9-cm Steel Reflector, VNIIEF \\
\hline & & \\
\hline umet3I & 1D & 8.0" Nickel-Reflected HEU (93.5) Sphere, Topsy Assembly \\
\hline
\end{tabular}


Table 9: Criticality Benchmark Descriptions for
Tungsten-Reflected Assemblies

\begin{tabular}{|c|c|l|}
\hline $\begin{array}{c}\text { MCNP } \\
\text { Filename }\end{array}$ & 1D/2D/3D & \multicolumn{1}{c|}{ Benchmark Description } \\
\hline $23 u m t 4 a$ & 1D & 0.96 " Tungsten-Reflected Sphere of U-233, Planet Assembly \\
\hline $23 u m t 4 b$ & 1D & $2.28 "$ Tungsten-Reflected Sphere of U-233, Planet Assembly \\
\hline umet3h & 1D & $1.9 "$ Tungsten Carbide-Reflected HEU (93.5) Sphere, Topsy Assembly \\
\hline umet3i & 1D & 2.9" Tungsten Carbide-Reflected HEU (93.5) Sphere, Topsy Assembly \\
\hline umet3j & 1D & $4.5 "$ Tungsten Carbide-Reflected HEU (93.5) Sphere, Topsy Assembly \\
\hline umet3k & 1D & $6.5 "$ Tungsten Carbide-Reflected HEU (93.5) Sphere, Topsy Assembly \\
\hline pumet5 & 1D & Tungsten-Reflected Pu (94.79) Sphere, Planet Assembly \\
\hline
\end{tabular}

Table 10: Criticality Benchmark Descriptions for Thorium-Reflected Assemblies

\begin{tabular}{|c|c|l|}
\hline $\begin{array}{c}\text { MCNP } \\
\text { Filename }\end{array}$ & 1D/2D/3D & \multicolumn{1}{|c|}{ Benchmark Description } \\
\hline pumet8a & 1D & Thorium-Reflected Pu (93.59) Sphere, Thor Assembly, 1D Model \\
\hline pumet8b & 2D & Thorium-Reflected Pu (93.59) Sphere, Thor Assembly, 2D Model \\
\hline
\end{tabular}

\section{Table 11: Criticality Benchmark Descriptions for Normal Uranium-Reflected Assemblies}

\begin{tabular}{|c|c|c|}
\hline $\begin{array}{l}\text { MCNP } \\
\text { Filename }\end{array}$ & 1D/2D/3D & Benchmark Description \\
\hline 23umt3a & $1 \mathrm{D}$ & $0.906 "$ Normal Uranium-Reflected Sphere of U-233, Planet Assembly \\
\hline 23umt3b & 10 & 2.09" Normal Uranium-Reflected Sphere of U-233, Planet Assembly \\
\hline $23 u m t 6$ & $1 \mathrm{D}$ & Flattop-23, 7.84" Normal Uranium-Reflected Sphere of U-233 \\
\hline flat23 & $1 \mathrm{D}$ & Flattop-23, CSEWG, U(N)-Reflected U-233 Sphere + Gap \\
\hline ieumt2 & $2 \mathrm{D}$ & $\begin{array}{l}\text { Reflected Jemima, U(N)-Reflected Cylindrical Disks of HEU and Natural } \\
\text { Uranium }\end{array}$ \\
\hline umet3a & $1 \mathrm{D}$ & 2" Tuballoy-Reflected HEU (93.5) Sphere, Topsy Assembly \\
\hline umet3b & $1 \mathrm{D}$ & 3" Tuballoy-Reflected HEU (93.5) Sphere, Topsy Assembly \\
\hline umet3c & $1 \mathrm{D}$ & 4" Tuballoy-Reflected HEU (93.5) Sphere, Topsy Assembly \\
\hline umet3d & 1D & 5" Tuballoy-Reflected HEU (93.5) Sphere, Topsy Assembly \\
\hline umet3e & $1 \mathrm{D}$ & 7" Tuballoy-Reflected HEU (93.5) Sphere, Topsy Assembly \\
\hline umet3f & $1 \mathrm{D}$ & 8" Tuballoy-Reflected HEU (93.5) Sphere, Topsy Assembly \\
\hline umet3g & 10 & 11" Tuballoy-Reflected HEU (93.5) Sphere, Topsy Assembly \\
\hline umet14 & 30 & Depleted Uranium-Reflected HEU ( 89.6) Sphere. VNIITF \\
\hline umet28 & $1 \mathrm{D}$ & Flattop-25, U(N)-Reflected HEU Sphere \\
\hline bigten1 & $1 D$ & Bigten, 1D Model: U(N)-Reflected Uranium Sphere \\
\hline bigten2 & 2D & Bigten, 2D Model: U(N)-Reflected Uranium Cylinder \\
\hline pumet6 & 1D & Normal Uranium-Reflected Pu (93.80) Sphere, Flattop Assembly \\
\hline pumet10 & $1 D$ & U(N)-Reflected Pu Sphere \\
\hline pumet20 & 3D & Depleted Uranium-Reflected Pu ( 90) Sphere, VNIITF \\
\hline
\end{tabular}


Table 12: Criticality Benchmark Descriptions for Highly Enriched Uranium-Reflected Assemblies

\begin{tabular}{|c|c|l|}
\hline $\begin{array}{c}\text { MCNP } \\
\text { Filename }\end{array}$ & 1D/2D/3D & \multicolumn{1}{c|}{ Benchmark Description } \\
\hline 23umt2a & 1D & $0.481 "$ HEU-Reflected Sphere of U-233; Planet Assembly \\
\hline 23umt2b & 1D & $0.783 "$ HEU-Reflected Sphere of U-233, Planet Assembly \\
\hline mixmet1 & 1D & HEU-Reflected Pu Sphere, Planet Assembly \\
\hline mixmet3 & 3D & HEU-Reflected Pu Sphere, VNIITF \\
\hline
\end{tabular}

Table 13: Criticality Benchmark Descriptions for Other Assemblies

\begin{tabular}{|c|c|l|}
\hline $\begin{array}{c}\text { MCNP } \\
\text { Filename }\end{array}$ & 1D/2D/3D & \multicolumn{1}{c|}{ Benchmark Description } \\
\hline ieumt1a & 2D & Jemima 1, Cylindrical Disks of HEU and Natural Uranium \\
\hline ieumt1b & 2D & Jemima 2, Cylindrical Disks of HEU and Natural Uranium \\
\hline ieumt1c & 2D & Jemima 3, Cylindrical Disks of HEU and Natural Uranium \\
\hline ieumt1d & 2D & Jemima 4, Cylindrical Disks of HEU and Natural Uranium \\
\hline mixmet8 & 3D & ZEBRA 8A/2, Graphite and Natural Uranium-Reflected Pu \\
\hline
\end{tabular}

\section{Nuclear Data Libraries}

The benchmark suite was run using MCNP version $4 B$ with two sets of nuclear data: ENDF/B-VI based data through Release 2 and ENDF/B-V based data (see Table 14). The ENDF/B-VI Release 2 data are contained in the ENDF60 nuclear data library. The ENDF/B-V based data are contained in a number of data libraries (RMCCS, ENDF5P, ENDF5U, etc.) and are composed of data having a ZAID ending of ".50c" or ".55c". The ".50c" indicates that the data were from ENDF/B-V Release 0 . In particular, ".55c" data were used for the following nuclides: ${ }^{2} \mathrm{H},{ }^{11} \mathrm{~B}, \mathrm{Fe},{ }^{182,183,184,186} \mathrm{~W},{ }^{237} \mathrm{~Np}$, and ${ }^{239} \mathrm{Pu}$. The replacement ZAID, $40000.56 \mathrm{c}$, for the original ".50c" data file was used for $\mathrm{Zr}$. Most of the important evaluations used in these benchmarks had major changes from $\mathrm{B}-\mathrm{V}$ to $\mathrm{B}-\mathrm{VI}$. Evaluations which remained essentially unchanged are ${ }^{27} \mathrm{Al}, \mathrm{Ga}$, ${ }^{182,183,184,186} \mathrm{~W},{ }^{232} \mathrm{Th},{ }^{233,234} \mathrm{U}$, and ${ }^{242} \mathrm{Pu}$. The ".55c" tungsten data were accepted for ENDF/B-V Release 2, and hence are equivalent to the ".60c" in ENDF60. Photon production data were added to the ${ }^{233} \mathrm{U}$ evaluation in 1981 , but this update will have no effect on $\mathrm{K}_{\text {eff }}$ calculations. The only differences between data sets for the unchanged evaluations are from changes in the processing of the evaluation into an MCNP data file 
using $\mathrm{NJOY}^{8}$ and should not be significant. Some of the major nuclides of interest were completely reevaluated for ENDF/B-VI. These include evaluations for the naturally occurring isotopes of $\mathrm{Cr}, \mathrm{Fe}, \mathrm{Ni}$, and $\mathrm{Cu}$. In the actinide region, ${ }^{235,238} \mathrm{U}$ and ${ }^{239,241} \mathrm{Pu}$ were completely updated, including an extension of the resonance region much higher in energy. These evaluation changes have been described elsewhere in more detail. ${ }^{9}$ For each benchmark, we used isotopic evaluations instead of elemental evaluations whenever possible, such as for the $W$ isotopes.

Table 14: ZAIDS Used from the Two Libraries

\begin{tabular}{|c|c|c|}
\hline Element & ENDF/B-V & ENDF/B-VI \\
\hline \multirow[t]{2}{*}{$\mathrm{H}$} & $1001.50 \mathrm{c}$ & $1001.60 \mathrm{c}$ \\
\hline & $1002.55 c$ & $1002.60 \mathrm{c}$ \\
\hline \multirow[t]{3}{*}{$\mathrm{Be}$} & $4009.50 \mathrm{c}$ & $4009.60 \mathrm{c}$ \\
\hline & $5010.50 \mathrm{c}$ & $5010.60 \mathrm{c}$ \\
\hline & $5011.55 c$ & $5011.60 c$ \\
\hline $\mathrm{C}$ & $6000.50 c$ & $6000.60 \mathrm{c}$ \\
\hline $\mathrm{N}$ & $7014.50 \mathrm{c}$ & $7014.60 \mathrm{c}$ \\
\hline 0 & $8016.50 c$ & $8016.60 c$ \\
\hline $\mathrm{Na}$ & $11023.50 \mathrm{c}$ & $11023.60 \mathrm{c}$ \\
\hline $\mathrm{Mg}$ & $12000.50 c$ & $12000.60 \mathrm{c}$ \\
\hline $\mathrm{Al}$ & $13027.50 \mathrm{c}$ & $13027.60 \mathrm{c}$ \\
\hline Si & $14000.50 \mathrm{c}$ & $14000.60 \mathrm{c}$ \\
\hline$P$ & $15031.50 \mathrm{c}$ & $15031.60 \mathrm{c}$ \\
\hline$S$ & $16032.50 \mathrm{c}$ & $16032.60 \mathrm{c}$ \\
\hline $\mathrm{Ca}$ & $20000.50 \mathrm{c}$ & $20000.60 \mathrm{c}$ \\
\hline $\mathrm{Ti}$ & $22000.50 c$ & $22000.60 c$ \\
\hline V & $23000.50 \mathrm{c}$ & $23000.60 \mathrm{c}$ \\
\hline \multirow[t]{4}{*}{$\mathrm{Cr}$} & $24000.50 \mathrm{c}$ & $24050.60 \mathrm{c}$ \\
\hline & & $24052.60 \mathrm{c}$ \\
\hline & & $24053.60 \mathrm{c}$ \\
\hline & & $24054.60 \mathrm{c}$ \\
\hline $\mathrm{Mn}$ & $25055.50 \mathrm{c}$ & $25055.60 \mathrm{c}$ \\
\hline \multirow[t]{4}{*}{$\mathrm{Fe}$} & $26000.55 c$ & $26054.60 \mathrm{c}$ \\
\hline & & $26056.60 \mathrm{c}$ \\
\hline & & $26057.60 \mathrm{c}$ \\
\hline & & $26058.60 \mathrm{c}$ \\
\hline
\end{tabular}

\begin{tabular}{|c|c|c|}
\hline Element & ENDF/B-V & ENDF/B-VI \\
\hline \multirow[t]{5}{*}{$\mathrm{Ni}$} & $28000.50 \mathrm{c}$ & $28058.60 \mathrm{c}$ \\
\hline & & $28060.60 \mathrm{c}$ \\
\hline & & $28061.60 \mathrm{c}$ \\
\hline & & $28062.60 \mathrm{c}$ \\
\hline & & $28064.60 \mathrm{c}$ \\
\hline \multirow[t]{2}{*}{$\mathrm{Cu}$} & $29000.50 \mathrm{c}$ & $29063.60 \mathrm{c}$ \\
\hline & & $29065.60 \mathrm{c}$ \\
\hline $\mathrm{Ga}$ & $31000.50 \mathrm{c}$ & $31000.60 \mathrm{c}$ \\
\hline $\mathrm{Zr}$ & $40000.56 \mathrm{c}$ & $40000.60 \mathrm{c}$ \\
\hline Mo & $42000.50 c$ & $42000.60 c$ \\
\hline $\mathrm{Cd}$ & $48000.50 \mathrm{c}$ & $48000.60 \mathrm{c}$ \\
\hline \multirow[t]{4}{*}{$W$} & $74182.55 \mathrm{c}$ & $74182.60 \mathrm{c}$ \\
\hline & $74183.55 \mathrm{c}$ & $74183.60 \mathrm{c}$ \\
\hline & $74184.55 \mathrm{c}$ & $74184.60 \mathrm{c}$ \\
\hline & $74186.55 \mathrm{c}$ & $74186.60 \mathrm{c}$ \\
\hline Th & $90232.50 \mathrm{c}$ & $90232.60 \mathrm{c}$ \\
\hline \multirow[t]{5}{*}{$U$} & $92233.50 \mathrm{c}$ & $92233.60 \mathrm{c}$ \\
\hline & $92234.50 \mathrm{c}$ & $92234.60 \mathrm{c}$ \\
\hline & $92235.50 \mathrm{c}$ & $92235.60 \mathrm{c}$ \\
\hline & $92236.50 \mathrm{c}$ & $92236.60 \mathrm{c}$ \\
\hline & $92238.50 \mathrm{c}$ & $92238.60 \mathrm{c}$ \\
\hline $\mathrm{Np}$ & $93237.55 \mathrm{c}$ & $93237.60 \mathrm{c}$ \\
\hline \multirow[t]{4}{*}{$\mathrm{Pu}$} & $94239.55 c$ & $94239.60 c$ \\
\hline & $94240.50 \mathrm{c}$ & $94240.60 \mathrm{c}$ \\
\hline & $94241.50 \mathrm{c}$ & $94241.60 \mathrm{c}$ \\
\hline & $94242.50 \mathrm{c}$ & $94242.60 \mathrm{c}$ \\
\hline $\mathrm{Am}$ & $95241.50 \mathrm{c}$ & $95241.60 \mathrm{c}$ \\
\hline
\end{tabular}




\section{Kesults}

Most of the calculations were performed on an HP-735 workstation. The solution assemblies and sensitivity calculations were performed on the Blue Mountain cluster of SGI Origin 2000s. There are a number of different ways to view the $k_{\text {eff }}$ results for these benchmarks. We have chosen to present the results by reflector material, or lack thereof. We have also grouped all of the solution assemblies together. When examining the results of the calculations by the five major categories of ${ }^{233} \mathrm{U}$, intermediate-enriched ${ }^{235} \mathrm{U}$ (IEU), highly enriched ${ }^{235} \mathrm{U}(\mathrm{HEU}),{ }^{239} \mathrm{Pu}$, and mixed metal assemblies, we find that on average there are few major changes in the results for the nonsolution ${ }^{233} \mathrm{U}, \mathrm{IEU},{ }^{239} \mathrm{Pu}$, and mixed metal assemblies. We do see a small decrease in $k_{\text {eff }}$ on average for the HEU metal assemblies $(-0.0011 \pm 0.0002)$ from the ENDF/B-V to the ENDF/B-VI Release 2 libraries. There is a consistent decrease in $k_{\text {eff }}$ for all of the solution assemblies between the B-V and B-VI libraries.

We will now examine the 13 sets of benchmarks in more detail. All results are quoted at the $2 \sigma$ level, which represents a confidence level of $95 \%$ that the true $k_{\text {eff }}$ for the calculation lies within the value quoted $+/-2 \sigma$. When one is considering this many benchmark calculations $(\sim 100)$, we can expect to see a few true $k_{\text {eff }}$ values that will lie outside of the quoted range based on statistics.

\section{A. Bare Metal Assemblies}

There are 9 bare metal assemblies in this suite of benchmarks. The Godiva assembly has two geometry descriptions: a simple sphere (umet1ss) and nested spherical shells (umet1ns) of HEU. Table 15 details the results for the bare metal assemblies and gives the benchmark $k_{\text {eff }}$ value. From these results we can see that the small changes in processing for the ${ }^{233} \mathrm{U}$ data make little difference in the calculated $k_{\text {eff }}$ value, and that the calculated $k_{\text {eff }}$ value is low. The one intermediate-enriched uranium benchmark (ieumt3, having $36 \mathrm{wt} . \%{ }^{235} \mathrm{U}$ and $63 \mathrm{wt} \%{ }^{238} \mathrm{U}$ ) shows a significant decrease between the $\mathrm{B}-\mathrm{V}$ and $\mathrm{B}-\mathrm{VI}$ data libraries, due to the changes in the ${ }^{235} \mathrm{U}$ evaluation. As we will see later in Section III.K for the normal uranium-reflected assemblies, the changes to the ${ }^{235} \mathrm{U}$ evaluation tend to decrease $k_{\text {eff, }}$, while the changes to the ${ }^{238} \mathrm{U}$ evaluation tend to increase $k_{\text {eff. }}$ For any given assembly, the energy 
spectrum and ratio of ${ }^{235} \mathrm{U}$ to ${ }^{238} \mathrm{U}$ will determine the net effect. The highly enriched uranium benchmarks tend to show a slight decrease in the $k_{\text {eff }}$ value, while the ${ }^{239} \mathrm{Pu}$ benchmarks show little change.

\section{Table 15: Criticality Benchmark Results for Bare Metal Assemblies}

\begin{tabular}{|c|c|c|c|}
\hline $\begin{array}{c}\text { MCNP } \\
\text { Filename }\end{array}$ & $\begin{array}{c}\text { Benchmark } \\
\mathbf{k}_{\text {eff }}\end{array}$ & ENDF/B-V & ENDF60 \\
\hline 23umt1 & $1.000 \pm 0.001$ & $0.9942 \pm 0.0011$ & $0.9931 \pm 0.0011$ \\
\hline ieumt3 & $1.0000 \pm 0.0017$ & $1.0051 \pm 0.0012$ & $1.0005 \pm 0.0012$ \\
\hline umet1ss & $1.000 \pm 0.001$ & $0.9982 \pm 0.0011$ & $0.9963 \pm 0.0012$ \\
\hline umet1ns & $1.000 \pm 0.001$ & $0.9975 \pm 0.0012$ & $0.9968 \pm 0.0011$ \\
\hline umet8 & $0.9989 \pm 0016$ & $0.9942 \pm 0.0012$ & $0.9918 \pm 0.0011$ \\
\hline umet15 & $0.9996 \pm 0.0017$ & $0.9931 \pm 0.0011$ & $0.9925 \pm 0.0011$ \\
\hline umet18 & $1.0000 \pm 0.0016$ & $0.9984 \pm 0.0011$ & $0.9969 \pm 0.0012$ \\
\hline pumet1 & $1.000 \pm 0.002$ & $0.9969 \pm 0.0012$ & $0.9971 \pm 0.0010$ \\
\hline pumet2 & $1.000 \pm 0.002$ & $0.9979 \pm 0.0011$ & $0.9992 \pm 0.0011$ \\
\hline pumet22 & $1.0000 \pm 0.0021$ & $0.9965 \pm 0.0011$ & $0.9962 \pm 0.0011$ \\
\hline
\end{tabular}

\section{B. Solution Assemblies}

Table 16 presents the results for the solution assemblies. With no exception, there is a significant decrease in $k_{\text {eff }}$ from $B-V$ to $B-V I$ data libraries. For the ${ }^{233} U$ and ${ }^{235} \mathrm{U}$ solutions, the decrease tends to move the calculations away from the benchmark value. The results for the ${ }^{239} \mathrm{Pu}$ solutions, however, are moved toward the benchmark value for $k_{\text {eff. }}$ We performed a large number of sensitivity tests for these assemblies. In each case, we used ENDF/B-V data for all isotopes, except the isotope of interest, where we used ENDF60 data. We then computed the mean value for the change in $k_{\text {eff }}$ for the set of assemblies. On average, the new ${ }^{1} \mathrm{H}$ evaluation decreased $\mathrm{k}_{\text {eff }}$ by $0.0010 \pm 0.0001$, while ${ }^{16} \mathrm{O}$ decreased $k_{\text {eff }}$ by $0.0026 \pm 0.0002$. There was no net effect due to the new ${ }^{14} \mathrm{~N}$ evaluation. The ${ }^{239} \mathrm{Pu}$ evaluation tended to decrease $\mathrm{k}_{\text {eff }}$ by $0.0033 \pm 0.0004$ for the plutonium solutions, and changes in the ${ }^{235} \mathrm{U}$ evaluation made very little difference in uranium solutions. 
Table 16: Criticality Benchmark Results for Solution Assemblies

\begin{tabular}{|c|c|c|c|}
\hline $\begin{array}{c}\text { MCNP } \\
\text { Filename }\end{array}$ & $\begin{array}{c}\text { Benchmark } \\
\mathbf{k}_{\text {eff }}\end{array}$ & ENDF/B-V & ENDF60 \\
\hline 23usl1a & $1.0000 \pm 0.0031$ & $1.0010 \pm 0.0007$ & $0.9967 \pm 0.0008$ \\
\hline 23usl1b & $1.0005 \pm 0.0033$ & $1.0004 \pm 0.0008$ & $0.9966 \pm 0.0008$ \\
\hline 23usl1c & $1.0006 \pm 0.0033$ & $0.9997 \pm 0.0008$ & $0.9969 \pm 0.0008$ \\
\hline 23usl1d & $0.9998 \pm 0.0033$ & $0.9993 \pm 0.0008$ & $0.9962 \pm 0.0008$ \\
\hline 23usl1e & $0.9999 \pm 0.0033$ & $0.9984 \pm 0.0008$ & $0.9956 \pm 0.0007$ \\
\hline 23usl8 & $1.0006 \pm 0.0029$ & $0.9987 \pm 0.0005$ & $0.9954 \pm 0.0005$ \\
\hline usol13a & $1.0012 \pm 0.0026$ & $1.0007 \pm 0.0008$ & $0.9972 \pm 0.0007$ \\
\hline usol13b & $1.0007 \pm 0.0036$ & $0.9993 \pm 0.0008$ & $0.9964 \pm 0.0008$ \\
\hline usol13c & $1.0009 \pm 0.0036$ & $0.9952 \pm 0.0009$ & $0.9922 \pm 0.0008$ \\
\hline usol13d & $1.0003 \pm 0.0036$ & $0.9981 \pm 0.0009$ & $0.9957 \pm 0.0009$ \\
\hline usol32 & $1.0015 \pm 0.0026$ & $1.0003 \pm 0.0005$ & $0.9966 \pm 0.0005$ \\
\hline pnl1 & $1.0(a)$ & $1.0158 \pm 0.0013$ & $1.0062 \pm 0.0012$ \\
\hline pnl6 & $1.0(a)$ & $1.0089 \pm 0.0013$ & $1.0020 \pm 0.0013$ \\
\hline pusl11a & $1.0000 \pm 0.0052$ & $1.0019 \pm 0.0011$ & $0.9951 \pm 0.0011$ \\
\hline pus/11b & $1.0000 \pm 0.0052$ & $1.0084 \pm 0.0012$ & $0.9998 \pm 0.0011$ \\
\hline pusl11c & $1.0000 \pm 0.0052$ & $1.0137 \pm 0.0013$ & $1.0045 \pm 0.0012$ \\
\hline pusl11d & $1.0000 \pm 0.0052$ & $1.0182 \pm 0.0012$ & $1.0085 \pm 0.0012$ \\
\hline
\end{tabular}

(a) Specific benchmark values were not given in the CSEWG specifications, and are assumed to be 1.0 .

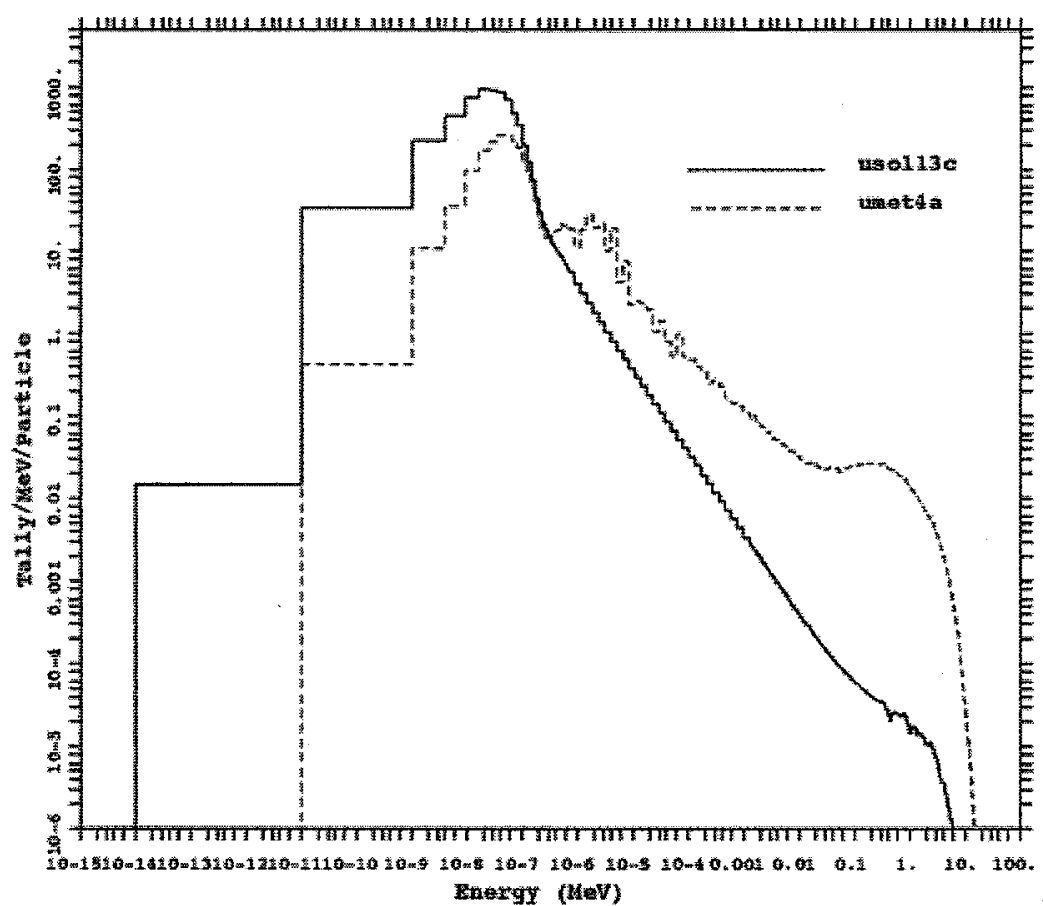

Figure 1: Comparison of Neutron Flux Spectra for USOL13C and UMET4A. 


\section{Water-Reflected Metal Assemblies}

There are 2 water-reflected assemblies. The water-reflected HEU sphere also has two descriptions: umet4a is a more complicated geometry, having the Plexiglas support ring included, and umet $4 \mathrm{~b}$ is a simpler geometry of the HEU sphere in a cylindrical tank of water.

Table 17 displays the results for the water-reflected spheres. There is an increase in $k_{\text {eff }}$ for the water-reflected HEU sphere, which is a net result of the new evaluation for hydrogen and oxygen that lowered $k_{\text {eff }}$ and the ${ }^{235} \mathrm{U}$ evaluation that increased $k_{\text {eff. }}$ Recall that there was little change in $k_{\text {eff }}$ due to the ${ }^{235} \mathrm{U}$ evaluation for the solution assemblies (Section III.B). The water-reflected HEU sphere (umet4a) has a harder neutron energy spectrum and a greater mass of ${ }^{235} \mathrm{U}$ than the uranium solution assemblies do. Hence, different energy regions of the evaluation are being exercised to differing extents. To illustrate this point, Figure 1 shows a comparison of the neutron energy spectrum over the solution assembly for usol13c with the central HEU sphere for umet4a.

The opposite trends due to changes in the ${ }^{235} \mathrm{U}$ evaluation for the metal systems in Section III.A and the water-reflected sphere of HEU can be understood by comparing the neutron energy spectrum over the core region of ieumt3 with umet4a. As Figure 2 shows, the neutron energy spectrum of umet4a is more of an intermediate energy spectrum and is softer than that of ieumt3. 
Table 17: Criticality Benchmark Results for Water-Reflected Metal Assemblies

\begin{tabular}{|c|c|c|c|}
\hline $\begin{array}{c}\text { MCNP } \\
\text { Filename }\end{array}$ & $\begin{array}{c}\text { Benchmark } \\
\mathbf{k}_{\text {eff }}\end{array}$ & ENDF/B-V & ENDF60 \\
\hline umet4a & 1.002 & $0.9999 \pm 0.0014$ & $1.0010 \pm 0.0015$ \\
\hline umet4b & $1.0003 \pm 0.0005$ & $0.9967 \pm 0.0015$ & $0.9969 \pm 0.0015$ \\
\hline pumet11 & $1.0000 \pm 0.001$ & $1.0009 \pm 0.0014$ & $0.9984 \pm 0.0014$ \\
\hline
\end{tabular}

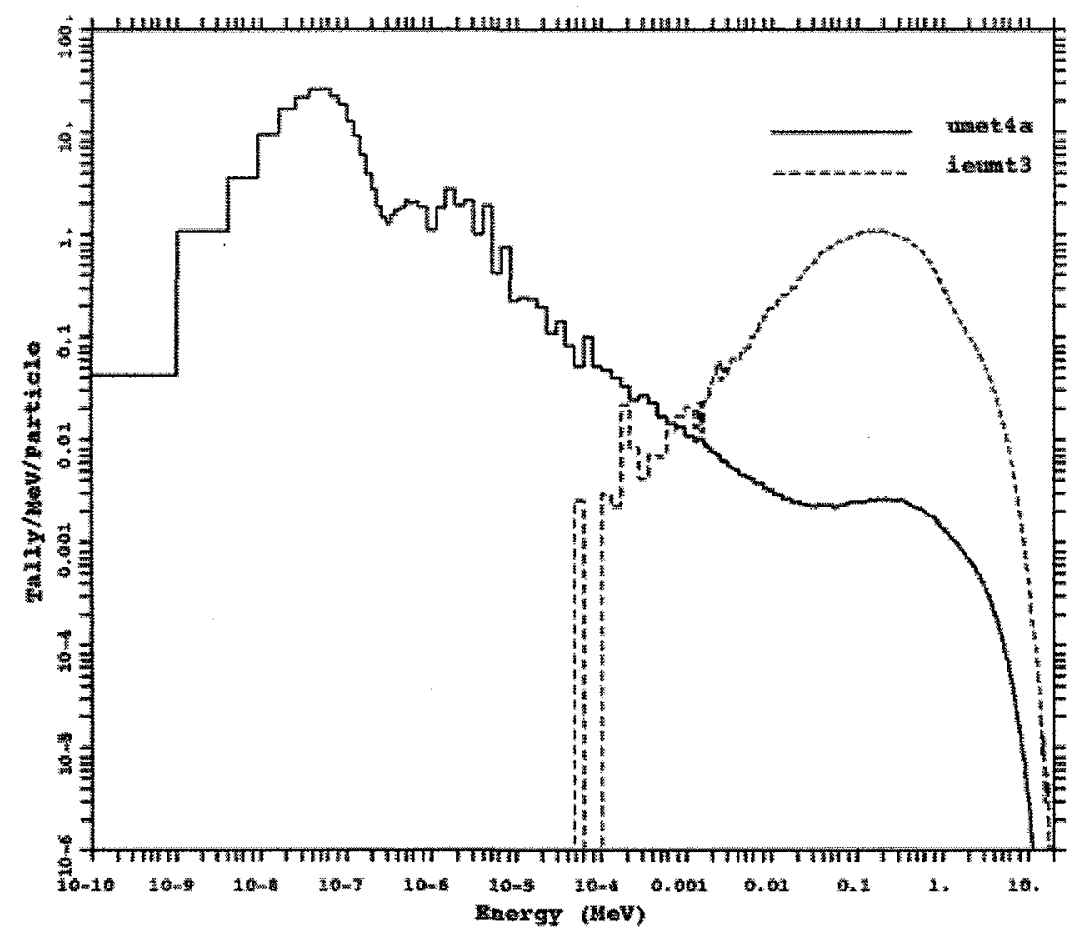

Figure 2: Comparison of Neutron Flux Spectrum for UMET4A and IEUMT3.

\section{Polyethylene-Reflected Assemblies}

Table 18 presents the calculational results for the polyethylene $\left(\mathrm{CH}_{2}\right)$-reflected assemblies. The solution experiments discussed previously in Section III.B indicated that there was a small decrease in $k_{\text {eff }}$ due to changes in the hydrogen evaluation. We performed sensitivity studies using B-V data for all isotopes except carbon, where we used ENDF60 data. These studies showed that changes to the carbon evaluation had a relatively negligible effect on $k_{\text {eff }}$ for these benchmarks. 
Table18: Criticality Benchmark Results for Polyethylene-Reflected Assemblies

\begin{tabular}{|c|c|c|c|}
\hline $\begin{array}{c}\text { MCNP } \\
\text { Filename }\end{array}$ & $\begin{array}{c}\text { Benchmark } \\
\mathbf{k}_{\text {eff }}\end{array}$ & ENDF/B-V & ENDF60 \\
\hline umet11 & $1.000 \pm 0.001$ & $0.9924 \pm 0.0014$ & $0.9954 \pm 0.0014$ \\
\hline umet20 & $1.0000 \pm 0.0030$ & $0.9958 \pm 0.0013$ & $0.9972 \pm 0.0013$ \\
\hline pumet24 & $1.0000 \pm 0.0020$ & $0.9981 \pm 0.0013$ & $1.0009 \pm 0.0012$ \\
\hline
\end{tabular}

\section{E. Beryllium- and Beryllium Oxide-Reflected Assemblies}

Table 19 gives the calculational results for the beryllium- and beryllium oxidereflected assemblies. There are two benchmarks - 23umt5a and umet9a-that showed a change of $\sim 2 \sigma$ for the beryllium-reflected assemblies. We ran these benchmarks again using a different starting random number (the eighth entry on the DBCN card). The new B-V and ENDF60 results for 23 umt5a were $0.9940 \pm 0.0012$ and $0.9941 \pm 0.0012$ respectively, illustrating that this $2 \sigma$ difference was due to statistical fluctuations. Sensitivity studies show that changes in the new beryllium ENDF/B-VI evaluation do not significantly affect the calculations, while the new ${ }^{16} \mathrm{O}$ evaluation lowers $k_{\text {eff }}$ by $0.0039+/-0.0006$ for the two beryllium-oxide benchmarks, umet $9 \mathrm{~b}$ and pumt21b.

Table 19: Criticality Benchmark Results for Beryllium and Beryllium-Oxide-Reflected Assemblies

\begin{tabular}{|c|c|c|c|}
\hline $\begin{array}{c}\text { MCNP } \\
\text { Filename }\end{array}$ & $\begin{array}{c}\text { Benchmark } \\
\mathbf{k}_{\text {eff }}\end{array}$ & ENDF/B-V & ENDF60 \\
\hline $23 u m t 5 a$ & $1.0000 \pm 0.0030$ & $0.9940 \pm 0.0012$ & $0.9962 \pm 0.0012$ \\
\hline $23 u m t 5 b$ & $1.0000 \pm 0.0030$ & $0.9955 \pm 0.0013$ & $0.9967 \pm 0.0014$ \\
\hline umet9a & $0.9992 \pm 0.0015$ & $0.9927 \pm 0.0012$ & $0.9958 \pm 0.0012$ \\
\hline umet9b & $0.9992 \pm 0.0015$ & $0.9962 \pm 0.0012$ & $0.9936 \pm 0.0012$ \\
\hline pumet18 & $1.0000 \pm 0.0030$ & $0.9999 \pm 0.0013$ & $0.9999 \pm 0.0012$ \\
\hline pumet19 & $0.9992 \pm 0.0015$ & $1.0016 \pm 0.0013$ & $1.0032 \pm 0.0012$ \\
\hline pumt21a & $1.0000 \pm 0.0026$ & $1.0033 \pm 0.0013$ & $1.0042 \pm 0.0013$ \\
\hline pumt21b & $1.0000 \pm 0.0026$ & $0.9970 \pm 0.0012$ & $0.9945 \pm 0.0012$ \\
\hline
\end{tabular}




\section{F. Graphite-Reflected Assemblies}

Table 20 gives the results from the calculations for the graphite-reflected assemblies. Only one assembly-ieumt4-shows a change greater than $2 \sigma$. We have seen a similar decrease in $k_{\text {eff }}$ for all of the IEU assemblies due to the changes in the ${ }^{235} \mathrm{U}$ evaluation $(-0.0042 \pm 0.0003)$. The ${ }^{238} \mathrm{U}$ evaluation has no significant impact on $\mathrm{k}_{\text {eff }}$ for the IEU assemblies. The changes to the carbon evaluation have a minimal effect on these benchmarks.

Table 20: Criticality Benchmark Results for Graphite-Reflected Assemblies

\begin{tabular}{|c|c|c|c|}
\hline $\begin{array}{c}\text { MCNP } \\
\text { Filename }\end{array}$ & $\begin{array}{c}\text { Benchmark } \\
\mathbf{k}_{\text {eff }}\end{array}$ & ENDF/B-V & ENDF60 \\
\hline ieumt4 & $1.0000 \pm 0.0030$ & $1.0091 \pm 0.0012$ & $1.0051 \pm 0.0012$ \\
\hline umet19 & $1.0000 \pm 0.0030$ & $1.0040 \pm 0.0012$ & $1.0031 \pm 0.0012$ \\
\hline pumet23 & $1.0000 \pm 0.0020$ & $0.9973 \pm 0.0012$ & $0.9973 \pm 0.0012$ \\
\hline
\end{tabular}

\section{G. Aluminum-Reflected Assemblies}

Table 21 shows the calculational results for the aluminum-reflected assemblies. There was no change in the aluminum evaluation between B-V and B-VI data. The changes in $k_{\text {eff }}$ from $B-V$ to $B-V I$ data are therefore due to changes in the fissionable isotopes. The largest change in $k_{\text {eff }}$ is for ieumt6, which shows a decrease similar to that seen for the other IEU assemblies from ${ }^{235} U$ (Section III.A, F, M).

Table 21: Criticality Benchmark Results for Aluminum-Reflected Assemblies

\begin{tabular}{|c|c|c|c|}
\hline $\begin{array}{c}\text { MCNP } \\
\text { Filename }\end{array}$ & $\begin{array}{c}\text { Benchmark } \\
\text { keff }_{\text {en }}\end{array}$ & ENDF/B-V & ENDF60 \\
\hline ieumt6 & $1.0000 \pm 0.0023$ & $0.9964 \pm 0.0012$ & $0.9917 \pm 0.0012$ \\
\hline umet12 & $0.9992 \pm 0.0018$ & $0.9932 \pm 0.0011$ & $0.9941 \pm 0.0012$ \\
\hline umet22 & $1.0000 \pm 0.0021$ & $0.9919 \pm 0.0012$ & $0.9924 \pm 0.0012$ \\
\hline pumet9 & $1.0000 \pm 0.0027$ & $1.0003 \pm 0.0012$ & $1.0022 \pm 0.0011$ \\
\hline
\end{tabular}




\section{H. Steel- and Nickel-Reflected Assemblies}

Table 22 presents the calculational results for the steel- and nickel-reflected assemblies. New isotopic evaluations for ENDF/B-VI for the isotopes of $\mathrm{Cr}, \mathrm{Fe}, \mathrm{Ni}$, and $\mathrm{Cu}$ replaced the previous elemental evaluations. The steel-reflected assemblies show a consistent decrease in $\mathrm{K}_{\text {eff }}$ from B-V to B-VI data. Sensitivity studies showed that there was an average decrease in $\mathrm{k}_{\text {eff }}$ due to the change from $\mathrm{B}-\mathrm{V}$ elemental evaluation to the isotopic $\mathrm{B}-\mathrm{VI}$ evaluations for iron of $0.0048 \pm 0.0006$ for these benchmarks. With the exception of ieumt5, this decrease tends to move the calculated $k_{\text {eff }}$ value further from the benchmark value. For ieumt5, the net decrease due to the changes in the Fe and ${ }^{235} \mathrm{U}$ evaluations make the calculation much closer to the benchmark.

For the nickel-reflected assembly, umet3I, sensitivity studies indicated that the change from the $B-V$ elemental evaluation to the isotopic $B-V I$ evaluations decreased $k_{\text {eff }}$ by $0.0104 \pm 0.0014$, moving it closer to the benchmark value.

Table 22: Criticality Benchmark Results for Steel- and Nickel-Reflected Assemblies

\begin{tabular}{|c|c|c|c|}
\hline $\begin{array}{c}\text { MCNP } \\
\text { Filename }\end{array}$ & $\begin{array}{c}\text { Benchmark } \\
\mathbf{k}_{\text {eff }}\end{array}$ & ENDF/B-V & ENDF60 \\
\hline \multicolumn{4}{|c|}{ Fe-Reflected } \\
\hline ieumt5 & $1.0000 \pm 0.0021$ & $1.0112 \pm 0.0011$ & $1.0007 \pm 0.0012$ \\
\hline umet13 & $0.9990 \pm 0.0015$ & $0.9982 \pm 0.0012$ & $0.9941 \pm 0.0013$ \\
\hline umet21 & $1.0000 \pm 0.0026$ & $1.0023 \pm 0.0012$ & $0.9947 \pm 0.0012$ \\
\hline pumet25 & $1.0000 \pm 0.0020$ & $0.9984 \pm 0.0012$ & $0.9963 \pm 0.0012$ \\
\hline pumet26 & $1.0000 \pm 0.0024$ & $1.0016 \pm 0.0012$ & $0.9971 \pm 0.0012$ \\
\hline \multicolumn{4}{|c|}{ Ni-Reflected } \\
\hline umet31 & $1.0000 \pm 0.0030$ & $1.0148 \pm 0.0013$ & $1.0049 \pm 0.0012$ \\
\hline
\end{tabular}

\section{Tungsten-Reflected Assemblies}

Table 23 presents the results for the tungsten-reflected assemblies. There are essentially no changes in the evaluations for tungsten isotopes between the B-V (".55c") and the B-VI data. Hence we do not expect to see large differences in the calculated $k_{\text {eff }}$ value. Only umet3h shows a significant change in $k_{\text {eff. }}$ We ran the ENDF60 version of this benchmark using a different random number for the starting history. The result was a $k_{\text {eff }}$ of $1.0049 \pm 0.0006$, indicating that the drop in $k_{\text {eff }}$ was a statistical fluctuation. 
Table 23: Criticality Benchmark Results for Tungsten-Reflected Assemblies

\begin{tabular}{|c|c|c|c|}
\hline $\begin{array}{c}\text { MCNP } \\
\text { Filename }\end{array}$ & $\begin{array}{c}\text { Benchmark } \\
\mathbf{k}_{\text {eff }}\end{array}$ & ENDF/B-V & ENDF60 \\
\hline $23 u m t 4 a$ & $1.0000 \pm 0.0007$ & $1.0037 \pm 0.0012$ & $1.0031 \pm 0.0012$ \\
\hline $23 u m t 4 b$ & $1.0000 \pm 0.0008$ & $1.0059 \pm 0.0013$ & $1.0049 \pm 0.0012$ \\
\hline umet3h & $1.0000 \pm 0.0050$ & $1.0055 \pm 0.0013$ & $1.0065 \pm 0.0013$ \\
\hline umet3i & $1.0000 \pm 0.0050$ & $1.0053 \pm 0.0012$ & $1.0066 \pm 0.0013$ \\
\hline umet3j & $1.0000 \pm 0.0050$ & $1.0056 \pm 0.0012$ & $1.0068 \pm 0.0013$ \\
\hline umet3k & $1.0000 \pm 0.0050$ & $1.0089 \pm 0.0012$ & $1.0094 \pm 0.0014$ \\
\hline pumet5 & $1.0000 \pm 0.0013$ & $1.0080 \pm 0.0013$ & $1.0102 \pm 0.0012$ \\
\hline
\end{tabular}

\section{J. Thorium-Reflected Assemblies}

There are two representations, one- and two-dimensional, of the Thor assembly, as Table 24 shows. As there were no changes in the evaluation for ${ }^{232} \mathrm{Th}$, the changes in $\mathrm{k}_{\text {eff }}$ for this benchmark are due to changes in the ${ }^{239} \mathrm{Pu}$ evaluation. The slight increase in $\mathrm{k}_{\text {eff }}$ follows the same pattern that we have seen for the Jezebel-Pu assemblies (pumet1 and pumet2) described in Section III.A.

Table 24: Criticality Benchmark Results for Thorium-Reflected Assemblies

\begin{tabular}{|c|c|c|c|}
\hline $\begin{array}{c}\text { MCNP } \\
\text { Filename }\end{array}$ & $\begin{array}{c}\text { Benchmark } \\
\mathbf{k}_{\text {eff }}\end{array}$ & ENDF/B-V & ENDF60 \\
\hline pumet8a & $1.0000 \pm 0.0030$ & $1.0042 \pm 0.0012$ & $1.0064 \pm 0.0012$ \\
\hline pumet8b & $1.000 \pm 0.0006$ & $1.0045 \pm 0.0013$ & $1.0072 \pm 0.0012$ \\
\hline
\end{tabular}

\section{K. Normal Uranium-Reflected Assemblies}

Table 25 gives the results for the normal uranium-reflected assemblies. There are 18 assemblies, one of which has two representations (Flattop-23). The ICSBEP geometry (23umt6) does not include a gap between the core and reflector as does the CSEWG specification (flat23). Half of the assemblies show a change in the calculated $k_{\text {eff }}$ of more than $2 \sigma$. The results are somewhat difficult to interpret as changes in both the ${ }^{235} \mathrm{U}$ and ${ }^{238} \mathrm{U}$ evaluations have competing effects. On average for these 
assemblies, the change in the ${ }^{235} \mathrm{U}$ evaluation caused a decrease in $\mathrm{k}_{\text {eff }}$ of $0.0022 \pm 0.0002$, while the changes in the ${ }^{238} \mathrm{U}$ evaluation caused an increase in $\mathrm{k}_{\text {eff }}$ of $0.0012 \pm 0.0002$. For assemblies having small net changes in $k_{\text {eff, }}$ the competing effects of the changes in the uranium evaluations tended to cancel each other. For example, in Bigten the changes to the ${ }^{235} \mathrm{U}$ evaluation decreased $\mathrm{k}_{\text {eff }}$ by 0.0065 , while the changes to the ${ }^{238} \mathrm{U}$ evaluation increased $\mathrm{k}_{\text {eff }}$ by 0.0084 .

Table 25: Criticality Benchmark Results for
Normal Uranium-Reflected Assemblies

\begin{tabular}{|c|c|c|c|}
\hline $\begin{array}{c}\text { MCNP } \\
\text { Filename }\end{array}$ & $\begin{array}{c}\text { Benchmark } \\
\mathbf{K}_{\text {eff }}\end{array}$ & ENDF/B-V & ENDF60 \\
\hline 23umt3a & $1.0000 \pm 0.0010$ & $0.9974 \pm 0.0011$ & $0.9971 \pm 0.0011$ \\
\hline 23umt3b & $1.0000 \pm 0.0010$ & $0.9983 \pm 0.0012$ & $0.9991 \pm 0.0012$ \\
\hline 23umt6 & $1.0000 \pm 0.0014$ & $0.9992 \pm 0.0013$ & $0.9997 \pm 0.0014$ \\
\hline flat23 & $1.000 \pm 0.001$ & $1.0030 \pm 0.0013$ & $1.0034 \pm 0.0013$ \\
\hline ieumt2 & $1.000 \pm 0.003$ & $1.0081 \pm 0.0011$ & $1.0034 \pm 0.0011$ \\
\hline umet3a & $1.0000 \pm 0.0050$ & $0.9954 \pm 0.0012$ & $0.9920 \pm 0.0012$ \\
\hline umet3b & $1.0000 \pm 0.0050$ & $0.9956 \pm 0.0012$ & $0.9936 \pm 0.0012$ \\
\hline umet3c & $1.0000 \pm 0.0050$ & $1.0006 \pm 0.0013$ & $0.9979 \pm 0.0013$ \\
\hline umet3d & $1.0000 \pm 0.0030$ & $0.9984 \pm 0.0012$ & $0.9950 \pm 0.0012$ \\
\hline umet3e & $1.0000 \pm 0.0030$ & $1.0029 \pm 0.0012$ & $1.0014 \pm 0.0013$ \\
\hline umet3f & $1.0000 \pm 0.0030$ & $1.0018 \pm 0.0012$ & $1.0006 \pm 0.0013$ \\
\hline umet3g & $1.0000 \pm 0.0030$ & $1.0039 \pm 0.0013$ & $1.0019 \pm 0.0013$ \\
\hline umet14 & $0.9989 \pm 0.0017$ & $0.9972 \pm 0.0013$ & $0.9957 \pm 0.0012$ \\
\hline umet28 & $1.0000 \pm 0.0030$ & $1.0030 \pm 0.0012$ & $1.0027 \pm 0.0013$ \\
\hline bigten1 & $0.996 \pm 0.003$ & $1.0059 \pm 0.0010$ & $1.0069 \pm 0.0010$ \\
\hline bigten2 & $0.996 \pm 0.003$ & $1.0035 \pm 0.0009$ & $1.0045 \pm 0.0009$ \\
\hline pumet6 & $1.0000 \pm 0.0030$ & $1.0039 \pm 0.0013$ & $1.0040 \pm 0.0014$ \\
\hline pumet10 & $1.0000 \pm 0.0018$ & $0.9984 \pm 0.0012$ & $1.0005 \pm 0.0012$ \\
\hline pumet20 & $0.9993 \pm 0.0017$ & $0.9998 \pm 0.0012$ & $0.9997 \pm 0.0013$ \\
\hline \multicolumn{3}{|l|}{}
\end{tabular}

\section{Highly Enriched Uranium-Reflected Assemblies}

Table 26 gives the results for the highly enriched uranium-reflected assemblies. The first two benchmarks, 23umt2a and 23umt2b, have a ${ }^{233} \mathrm{U}$ core, while mixmet1 and mixmet3 have a ${ }^{239} \mathrm{Pu}$ core. Recall that the evaluation for ${ }^{233} \mathrm{U}$ did not change from $\mathrm{B}-\mathrm{V}$ to B-VI (Section II). The decrease in $\mathrm{k}_{\text {eff }}$ for $23 \mathrm{umt} 2 \mathrm{~b}$ illustrates that the larger the HEU 
reflector, the larger the decrease in $k_{\text {eff. }}$ We see a similar trend for the two benchmarks having a ${ }^{239} \mathrm{Pu}$ core.

Table 26: Criticality Benchmark Results for Highly Enriched Uranium-Reflected Assemblies

\begin{tabular}{|c|c|c|c|}
\hline $\begin{array}{c}\text { MCNP } \\
\text { Filename }\end{array}$ & $\begin{array}{c}\text { Benchmark } \\
\mathbf{k}_{\text {eff }}\end{array}$ & ENDF/B-V & ENDF60 \\
\hline 23umt2a & $1.0000 \pm 0.0010$ & $0.9952 \pm 0.0011$ & $0.9961 \pm 0.0011$ \\
\hline 23umt2b & $1.0000 \pm 0.0011$ & $0.9991 \pm 0.0011$ & $0.9968 \pm 0.0011$ \\
\hline mixmet1 & $1.0000 \pm 0.0016$ & $0.9966 \pm 0.0012$ & $0.9969 \pm 0.0012$ \\
\hline mixmet3 & $0.9993 \pm 0.0016$ & $1.0000 \pm 0.0012$ & $0.9979 \pm 0.0012$ \\
\hline
\end{tabular}

\section{Other Assemblies}

Table 27 presents the results for other assemblies. The ieumt1 (Jemima) series of benchmarks are cylindrical disks of HEU and normal uranium. The MCNP model is slightly idealized, but still maintains the heterogeneous description of the disks. It has been shown that performing a criticality calculation using a homogenous material gives too large a discrepancy in $\mathrm{k}_{\text {eff }}{ }^{5}$ The changes to the ${ }^{235} \mathrm{U}$ evaluation tend to decrease $\mathrm{k}_{\text {eff }}$ for the Jemima assemblies $(-0.0032 \pm 0.0004)$, and are greater than changes in $k_{\text {eff }}$ due the new ${ }^{238} \mathrm{U}$ evaluation. As discussed previously in Section III.F, this same trend is evident in all of the IEU assemblies.

Table 27: Criticality Benchmark Results for Other Assemblies

\begin{tabular}{|c|c|c|c|}
\hline $\begin{array}{c}\text { MCNP } \\
\text { Filename }\end{array}$ & $\begin{array}{c}\text { Benchmark } \\
\mathbf{k}_{\text {eff }}\end{array}$ & ENDF/B-V & ENDF60 \\
\hline mixmet8 & $0.9920 \pm 0.0063$ & $0.9591 \pm 0.0009$ & $0.9918 \pm 0.0010$ \\
\hline ieumt1a & 0.9989 & $1.0024 \pm 0.0012$ & $0.9961 \pm 0.0012$ \\
\hline ieumt1b & 0.9997 & $1.0018 \pm 0.0012$ & $0.9974 \pm 0.0012$ \\
\hline ieumt1c & 0.9993 & $1.0035 \pm 0.0012$ & $0.9988 \pm 0.0012$ \\
\hline ieumt1d & 1.0002 & $1.0039 \pm 0.0012$ & $0.9984 \pm 0.0012$ \\
\hline
\end{tabular}

The mixmet8 assembly is a rectangular graphite- and normal uranium-reflected slab of ${ }^{239} \mathrm{Pu}$ illustrated in Figure 3 . This is a $k_{\infty}$ calculation such that the geometry in 
Figure 3 has periodic boundaries for the outer surfaces normal to the $x$ - and $z$-axes shown in the figure. The outer surfaces perpendicular to the $y$-axis are reflective. For more details on the geometry, see the MIX-MET-FAST-008 specifications in reference 5.

There is a large discrepancy in the mixmet8 calculations using ENDF/B-V to B-VI data. This change in $k_{\text {eff }}$ is due to changes in the evaluation for ${ }^{238} U$. Sensitivity tests showed that there was little effect from the new evaluations for ${ }^{235} \mathrm{U},{ }^{239} \mathrm{Pu}$, and ${ }^{54,56,57,58} \mathrm{Fe}$, but that the ${ }^{238} \mathrm{U}$ evaluation increased $\mathrm{k}_{\text {eff }}$ by $0.0265 \pm 0.0007$. Figures $4-6$ illustrate the difference in neutron flux through the $\mathrm{Pu}$, graphite $(\mathrm{C})$, and $\mathrm{U}$ regions for the $B-V$ and $B-V I$ calculations. These figures show a systematic increase in the neutron flux below $10 \mathrm{keV}$ for the ENDF/B-VI data. This result is most probably due to changes in the ${ }^{238} \mathrm{U}$ evaluation below $10 \mathrm{keV}$, where the resonance region was reevaluated and extended from $4 \mathrm{keV}$ to $10 \mathrm{keV}$ for ENDF/B-VI. Figure 7 illustrates how thermal the neutron energy spectrum is for mixmet8 when compared to other uranium-reflected benchmarks such as Bigten. Therefore, the resonance region has a greater impact on $k_{\text {eff. }}$ Figures 8 and 9 illustrate the changes in the total cross section and total nubar data for ${ }^{238} \mathrm{U}$ in the lower energy regions. These changes substantially improve the ${ }^{238} \mathrm{U}$ evaluation for use in thermal systems.

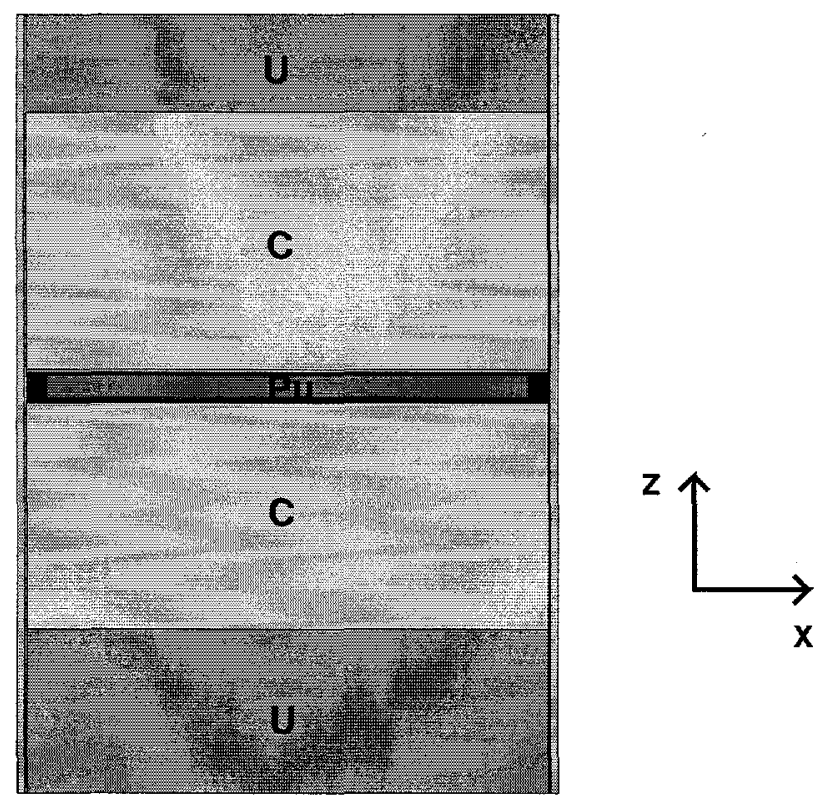

Figure 3: The Graphite and Normal Uranium-Reflected Slab of ${ }^{239}$ Pu Geometry, MIXMET8. The outer surfaces are periodic. 


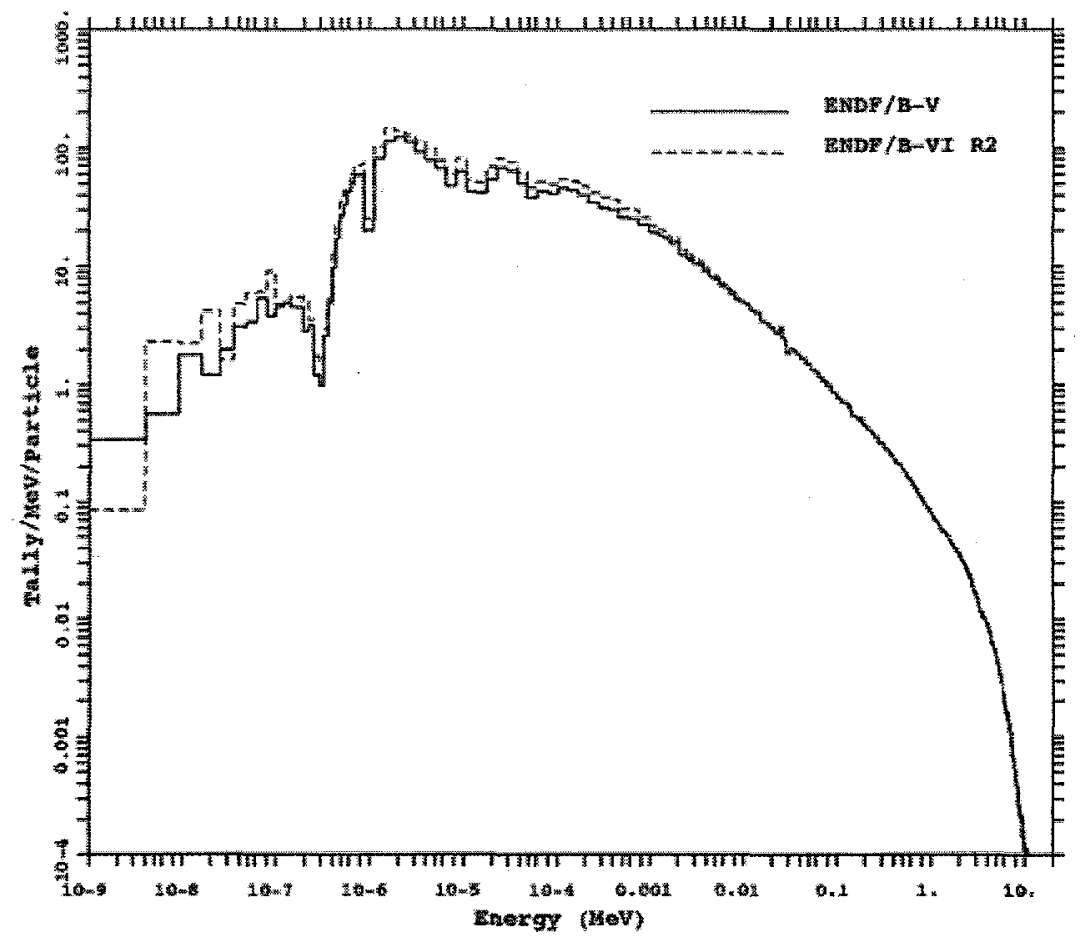

Figure 4: Comparison of Neutron Flux in Central Pu Region of MIXMET8.

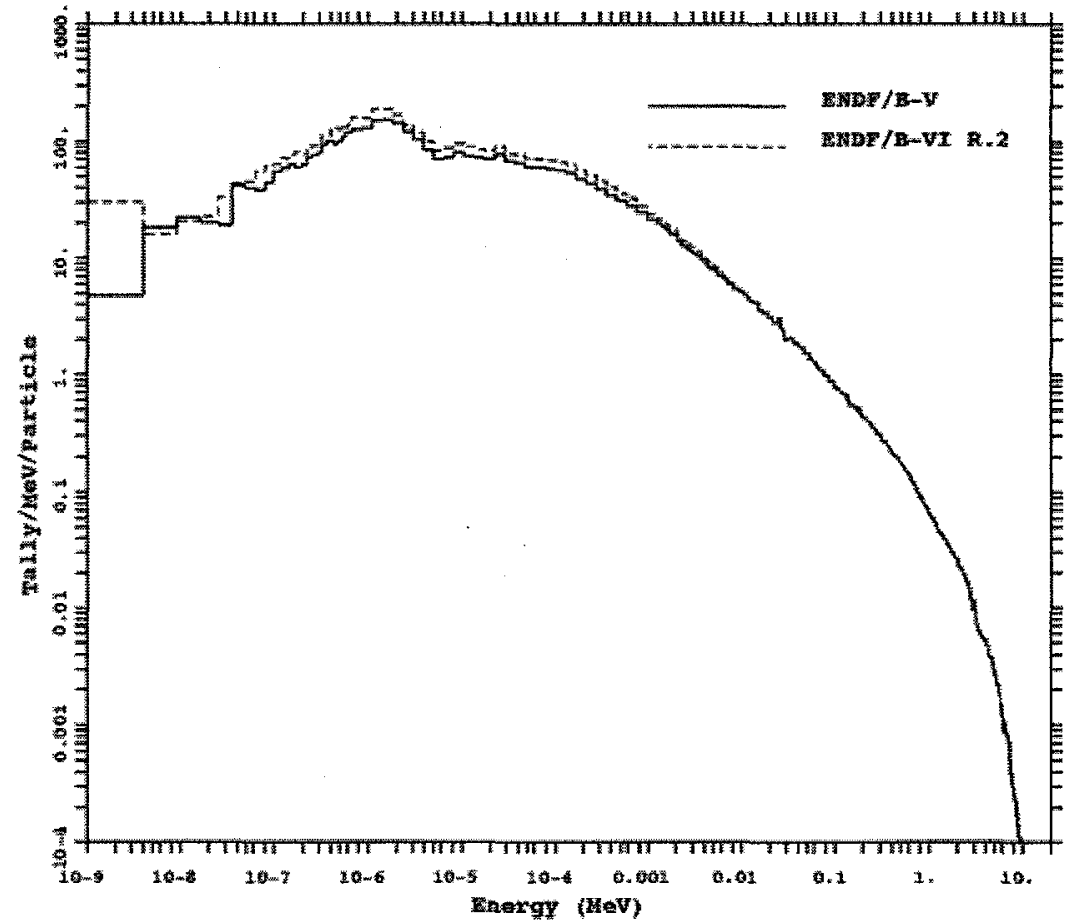

Figure 5: Comparison of Neutron Flux in Graphite Reflector of MIXMET8. 


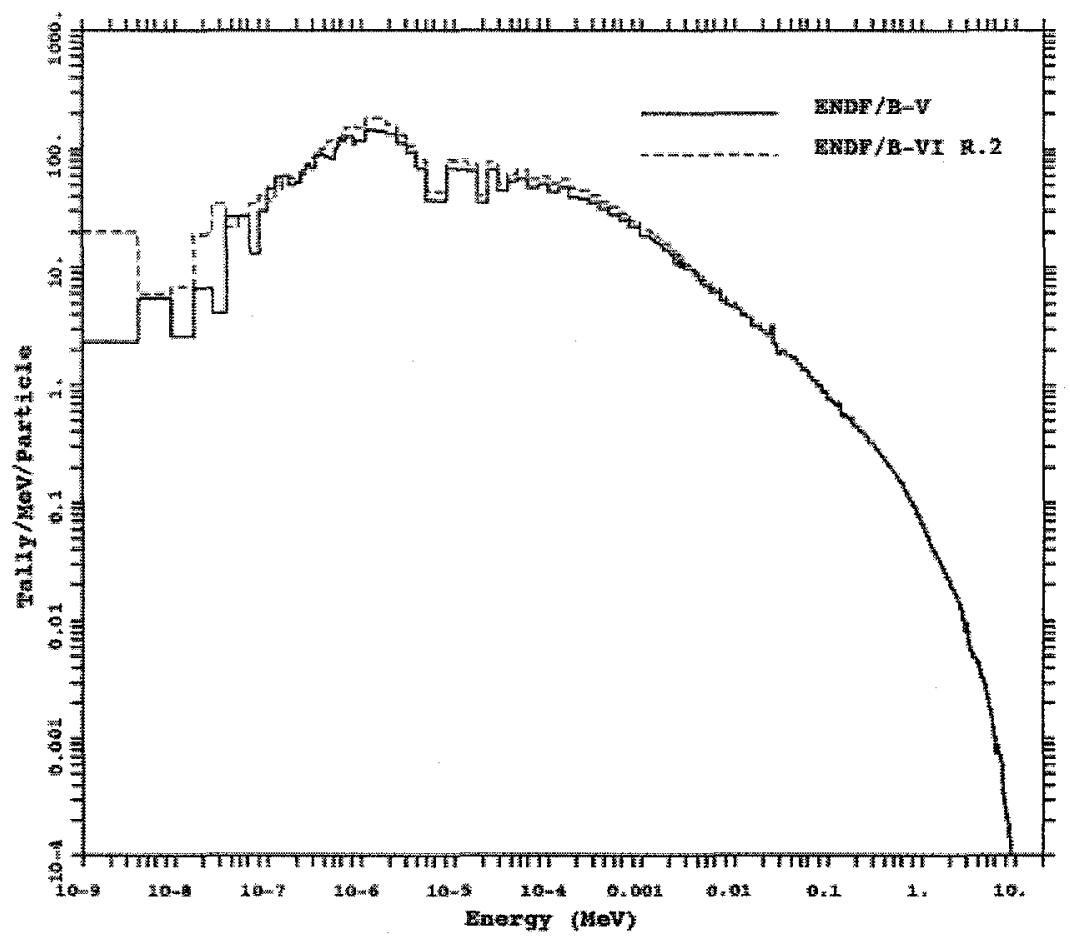

Figure 6: Comparison of Neutron Flux in the Uranium Reflector of MIXMET8.

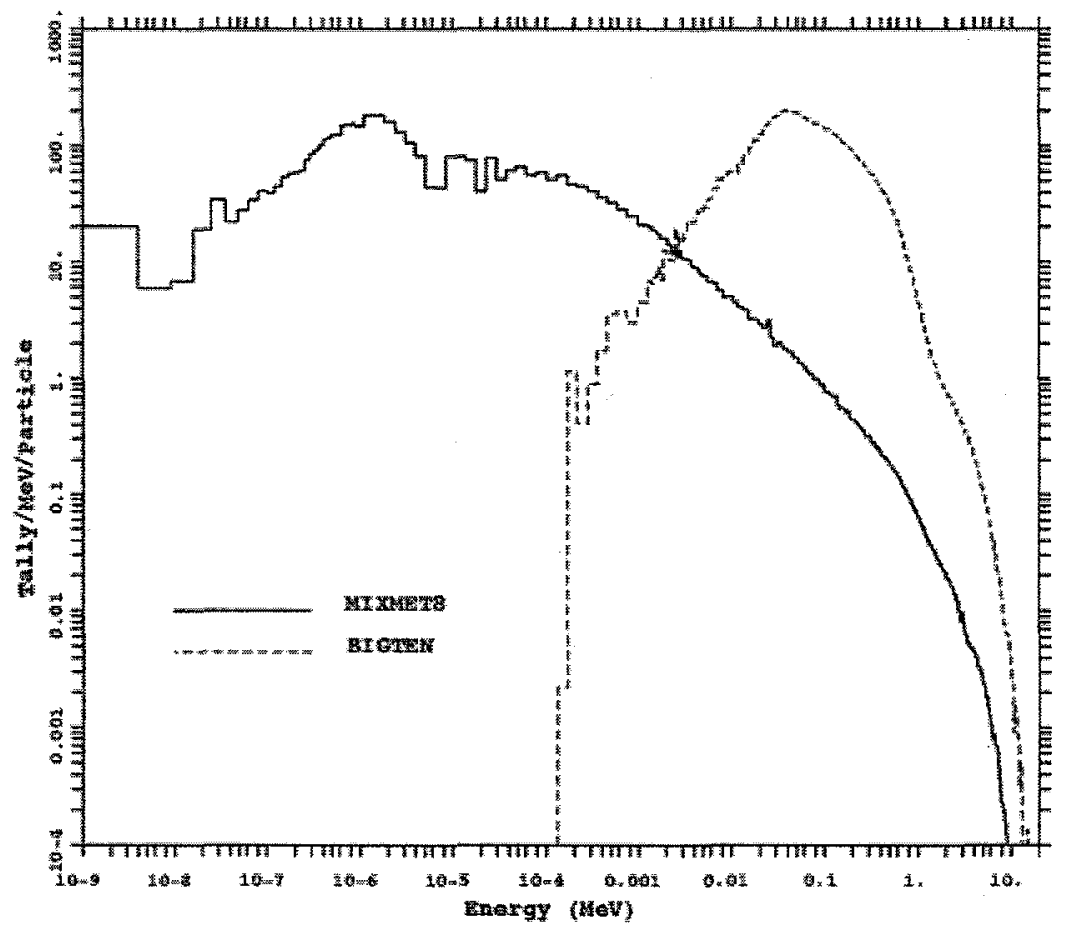

Figure 7: Comparison of Neutron Flux in the Uranium Reflector of MIXMET8 and BIGTEN using ENDF/B-VI Data. 


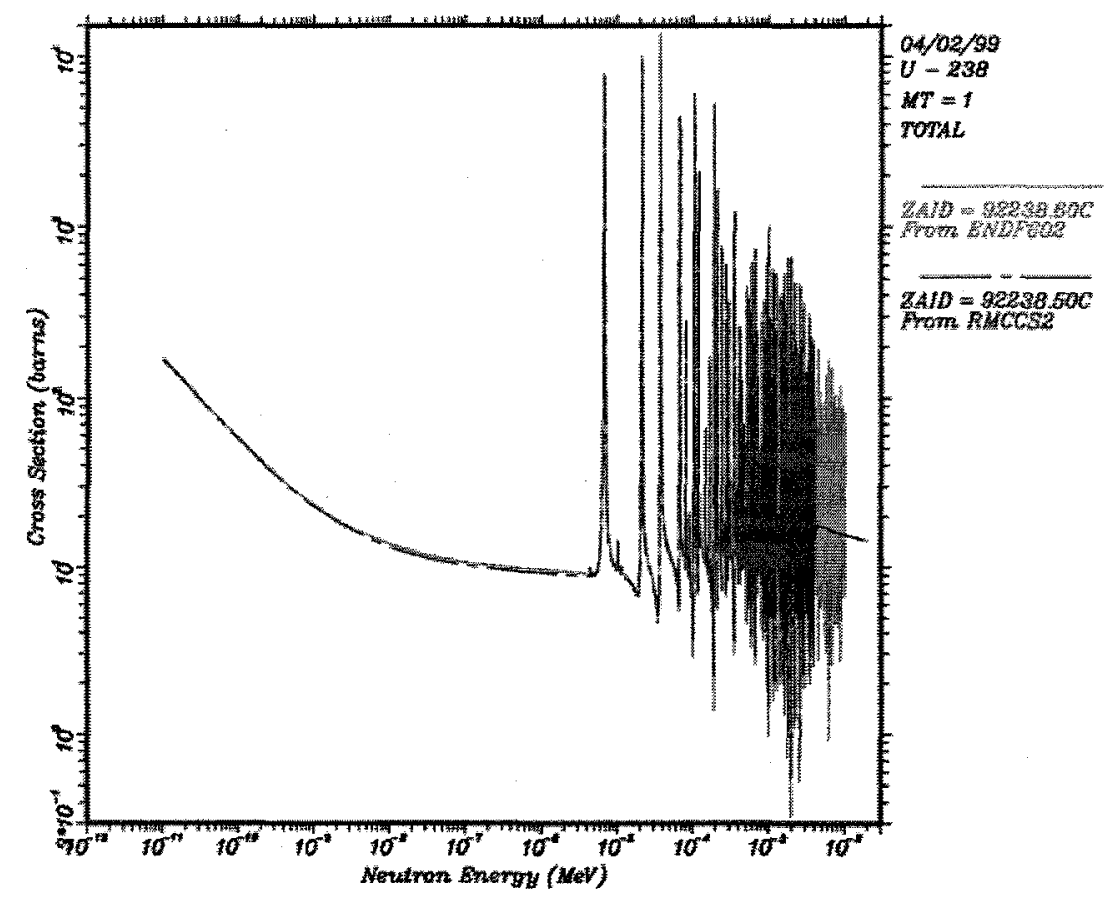

Figure 8: Comparison of the ENDF/B-VI and B-V Total Cross Sections for U-238.

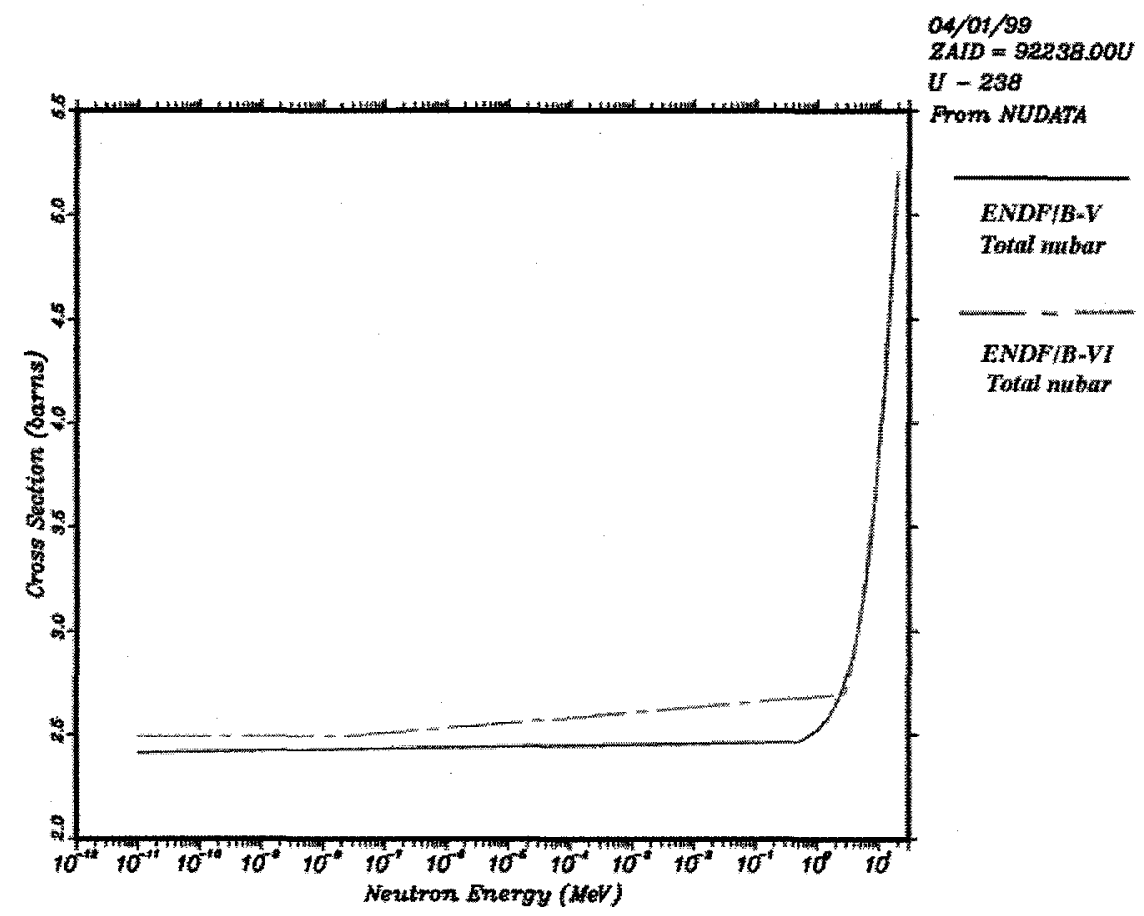

Figure 9: Comparison of the Total Nubar Data for U-238. 


\section{Summary}

A suite of 86 criticality benchmarks for MCNP has been calculated using two sets of continuous-energy neutron data libraries: ENDF/B-VI based data through Release 2 and the ENDF/B-V based data. New evaluations were completed for ENDF/B-VI for a number of the important nuclides such as the isotopes of $\mathrm{H}, \mathrm{Be}, \mathrm{C}, \mathrm{N}, \mathrm{O}, \mathrm{Fe}, \mathrm{Ni},{ }^{235,238} \mathrm{U}$, ${ }^{237} \mathrm{~Np}$, and ${ }^{239,240} \mathrm{Pu}$. While this suite of benchmarks covers a wide range of energies and materials, it is no means complete. We anticipate that benchmarks will continue to be added to the suite in the future.

The new evaluations for ${ }^{9} \mathrm{Be},{ }^{12} \mathrm{C}$, and ${ }^{14} \mathrm{~N}$ showed no net effect on $\mathrm{k}_{\text {eff. }}$ The results of the solution assemblies indicate that there is a significant decrease in $k_{\text {eff }}$ due to the changes in the ${ }^{1} \mathrm{H}$ and ${ }^{16} \mathrm{O}$ evaluations. For the ${ }^{233} \mathrm{U}$ and ${ }^{235} \mathrm{U}$ solution assemblies, this tends to move the $k_{\text {eff }}$ value further from the benchmark value, while it tends to move the $k_{\text {eff }}$ closer to the benchmark value for ${ }^{239} \mathrm{Pu}$ solutions.

The new evaluations for the $\mathrm{Fe}$ and $\mathrm{Ni}$ isotopes decreased $\mathrm{k}_{\text {eff }}$ for the steel- and nickel-reflected assemblies. For $\mathrm{Fe}$, this moved the calculated $\mathrm{k}_{\text {eff }}$ further from the benchmark value, while the new $\mathrm{Ni}$ data moved the calculation closer to the benchmark value. The isotopic tungsten data remained unchanged from $B-V$ to $B-V I$. The tungsten-reflected assemblies tend to calculate slightly higher than the benchmark values.

Recall that the evaluation for ${ }^{233} \mathrm{U}$ remained unchanged from ENDF/B-V to $\mathrm{B}-\mathrm{V}$, with the exception of the addition of photon production data, which will not affect $k_{\text {eff }}$ calculations. For ${ }^{233} U$, we find that the one metal assembly, Jezebel-23, calculates slightly low for $k_{\text {eff. }}$ The solution assemblies show a drop in $k_{\text {eff }}$ when using the ENDF/B$\mathrm{VI}$ based data due to the changes in the ${ }^{1} \mathrm{H}$ and ${ }^{16} \mathrm{O}$ evaluations. For the uranium solutions this tended to move the calculated $k_{\text {eff }}$ further from the benchmark value, while it moved the calculated $k_{\text {eff }}$ value closer to the benchmark value for plutonium solutions.

For ${ }^{235} \mathrm{U}$ and ${ }^{238} \mathrm{U}$, we find that for metal (fast) systems, the ENDF/B-VI data for ${ }^{235} \mathrm{U}$ tends to decrease $\mathrm{k}_{\text {eff }}$ while the ${ }^{238} \mathrm{U}$ data tends to increase $k_{\text {eff. }}$ For a given assembly, the energy spectrum and material specifications will determine the net effect for $k_{\text {eff. }}$ The HEU metal assemblies tend to show a slight decrease in $k_{\text {eff }}$ when using the $\mathrm{B}-\mathrm{VI}$ data due to ${ }^{235} \mathrm{U}$. For the more thermal system of the water-reflected HEU 
sphere, the ${ }^{235} \mathrm{U}$ data increased $\mathrm{k}_{\text {eff. }}$. For the ${ }^{235} \mathrm{U}$ solution assemblies, the changes to the ${ }^{235} \mathrm{U}$ evaluation made very little difference.

For the one mixed graphite and $\mathrm{U}(\mathrm{N})$-reflected assembly, a large increase in $\mathrm{K}_{\text {eff }}$ due to changes in the ${ }^{238} \mathrm{U}$ evaluation moved the calculated $k_{\text {eff }}$ much closer to the benchmark value. This result is most probably due to changes below $10 \mathrm{keV}$ where the resonance region was re-evaluated and extended from $4 \mathrm{keV}$ to $10 \mathrm{keV}$ for ENDF/B-VI. The significance of this change indicates the need for more composite benchmarks to exercise as many different energy regions as possible.

There is little change in $\mathrm{k}_{\text {eff }}$ for the ${ }^{239} \mathrm{Pu}$ metal assemblies. For the solution assemblies, the changes in the ${ }^{239} \mathrm{Pu}$ evaluation tended to decrease $\mathrm{k}_{\mathrm{eff}}$, moving the value closer to the benchmark value.

\section{Acknowledgments}

The author gratefully acknowledges the value of many useful discussions with Robert Little and Harold Rogers. The assistance of Judi Briesmeister and Art Forster is greatly appreciated in finalizing aspects of the MCNP specifications and interpreting the MCNP output. 


\section{References}

1 J. F. Briesmeister, Ed., "MCNP4B - A General Monte Carlo N-Particle Transport Code," Los Alamos National Laboratory report LA-12625-M (1997).

2 S. C. Frankle, "A Suite of Criticality Benchmarks for Validating Nuclear Data," Los Alamos National Laboratory report LA-13594 (1999).

$3 \quad$ P. Jaegers and R. Sanchez, "Intermediate Neutron Spectrum Problems and the Intermediate Neutron Spectrum Experiment," Proceedings of the International Topical Meeting on Nuclear and Hazardous Waste Management (American Nuclear Society, La Grange Park, IL, 1996).

$4 \quad$ "Cross Section Evaluation Working Group Benchmark Specifications," ENDF202, Brookhaven National Laboratory report BNL 19302 (revised 1991).

5 "International Handbook of Evaluated Criticality Safety Benchmark Experiments," NEA Nuclear Science Committee, NEA/NSC/DOC (95)03, 1998 Edition, (http://wastenot.inel.gov/icsbep/handbook.html).

$6 \quad$ J. S. Hendricks, S. C. Frankle, and J. D. Court, "ENDF/B-VI Data for MCNP," Los Alamos National Laboratory report LA-12891 (1994).

7 S. C. Frankle, "Spectral Measurements in Critical Assemblies: MCNP Specifications and Calculated Results," Los Alamos National Laboratory report, to be published in 1999.

8 R. E. MacFarlane and D. W. Muir, "The NJOY Nuclear Data Processing System, Version 91," Los Alamos National Laboratory report LA-12740-M and UC-413 (1994).

9 R. D. Mosteller, S. C. Frankle, and P. G. Young, "Data Testing of ENDF/B-VI with MCNP: Critical Experiments, Thermal-Reactor Lattices, and Time-of-Flight Measurements," Advances in Nuclear Science and Technology 24, 131 (1997). 